\title{
Views of health care providers on low-income populations in West Virginia with sexually transmitted disease
}

Genevieve R. Cox

West Virginia University

Follow this and additional works at: https://researchrepository.wvu.edu/etd

\section{Recommended Citation}

Cox, Genevieve R., "Views of health care providers on low-income populations in West Virginia with sexually transmitted disease" (2005). Graduate Theses, Dissertations, and Problem Reports. 837. https://researchrepository.wvu.edu/etd/837

This Thesis is protected by copyright and/or related rights. It has been brought to you by the The Research Repository @ WVU with permission from the rights-holder(s). You are free to use this Thesis in any way that is permitted by the copyright and related rights legislation that applies to your use. For other uses you must obtain permission from the rights-holder(s) directly, unless additional rights are indicated by a Creative Commons license in the record and/ or on the work itself. This Thesis has been accepted for inclusion in WVU Graduate Theses, Dissertations, and Problem Reports collection by an authorized administrator of The Research Repository @ WVU. For more information, please contact researchrepository@mail.wvu.edu. 


\title{
Views of Health Care Providers on Low-Income Populations in West Virginia with Sexually Transmitted Disease
}

\author{
Genevieve R. Cox
}
Thesis submitted to the College of Arts and Sciences
at West Virginia University
in partial fulfillment of the requirements
for the degree of

\author{
Master of Arts \\ in \\ Applied Social Research
}

\begin{abstract}
Melissa Latimer, Ph.D., Chair
Beverly Smith, Ph.D., M.D.

Rachael Woldoff, Ph.D.
\end{abstract}
Morgantown, West Virginia
2005

Copyright 2005 Genevieve R. Cox 


\section{Abstract \\ Views of Health Care Providers on Low-Income Populations in West Virginia with Sexually Transmitted Disease}

\section{Genevieve R. Cox}

This thesis focuses on health care providers who consistently diagnose sexually transmitted disease (STDs) in low-income populations. Eighteen providers ranging from registered nurses to physicians were interviewed about their experiences dealing with low-income patients, mainly women, who were diagnosed with incurable and curable STDs for the first time. This qualitative analysis which utilized grounded theory methods reveals several interesting finding. First, that providers who consistently work with lowincome populations have a high level of empathy. They believe patients undergo a negative change in self-image second to an incurable STD diagnosis. Providers have concerns about a number of issues related to low-income women's access to care and see the need for more sexuality education, more funding for free and reduced cost clinics, and more health insurance. Many providers would also like to see the stigma attached to having an STD eradicated. 


\section{Dedication}

This research is dedicated to health care providers, researchers, and activists engaged in

public practice and service who work for reproductive freedom and universal access to health care for all individuals regardless of income level. 


\section{Acknowledgements}

I would like to acknowledge the providers who so generously donated their time for

interviews, the clinics who allowed my entrance into their world, the librarians who navigate our interlibrary loan system, and my committee. 


\section{Table of Contents}

Views of Health Care Providers on Low-Income Populations in West Virginia with Sexually Transmitted Disease ...............................................................................

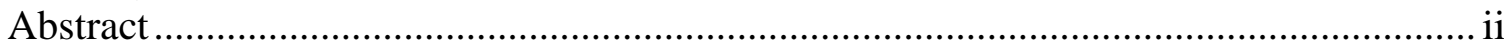

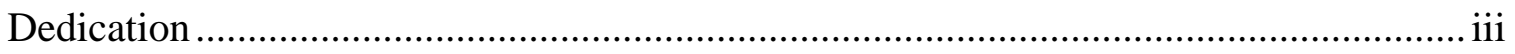

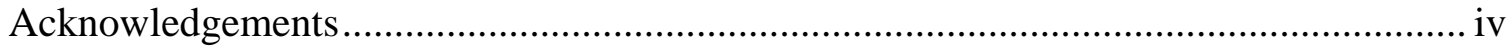

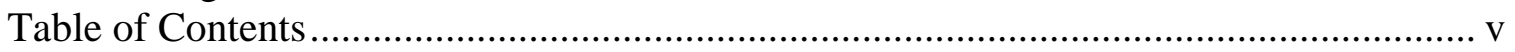

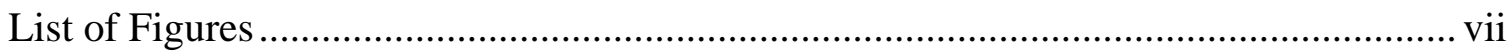

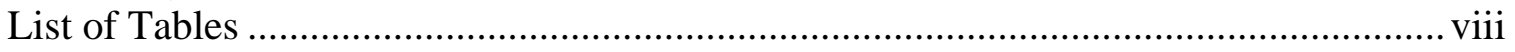

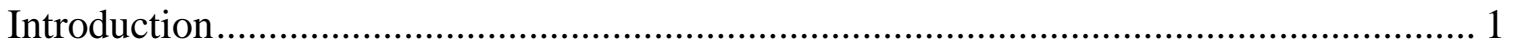

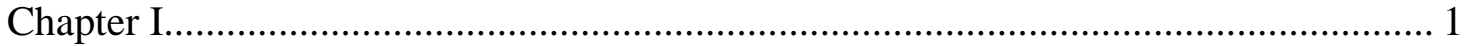

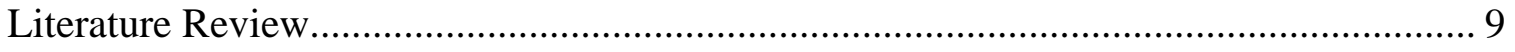

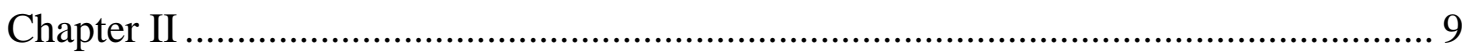

Sexually Transmitted Disease/Sexually Transmitted Infection ................................ 9

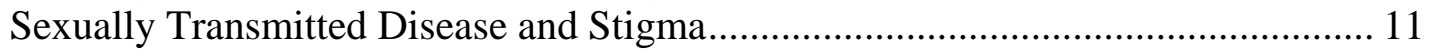

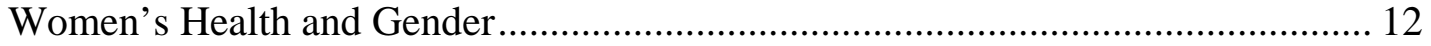

Socioeconomic Status, Health Insurance, and West Virginia................................ 13

Access to Care and Socioeconomic Status ............................................................ 15

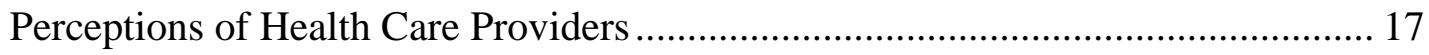

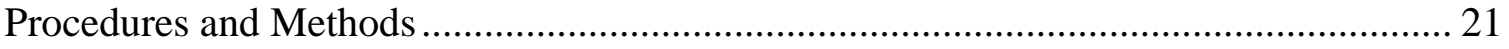

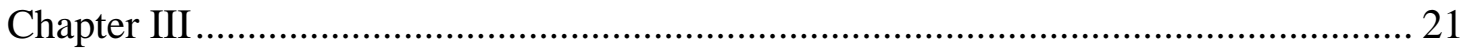

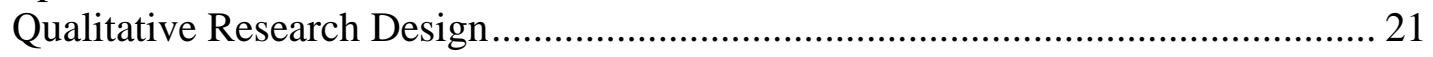

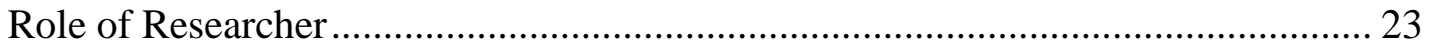

Dimensional Analysis and Grounded Theory Research Strategy ............................ 24

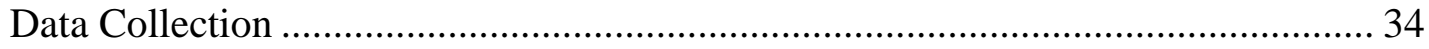

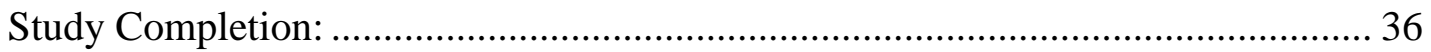

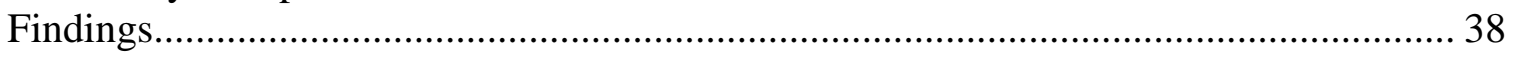

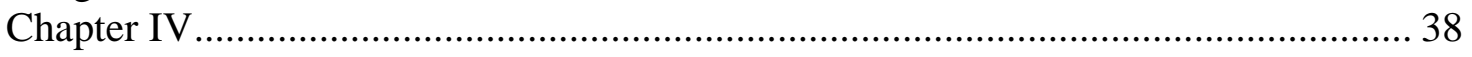

Providers’ Views of Patients: STD Diagnostic Sessions ........................................ 39

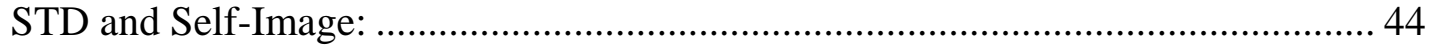

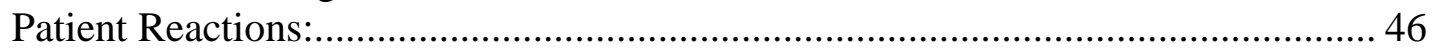

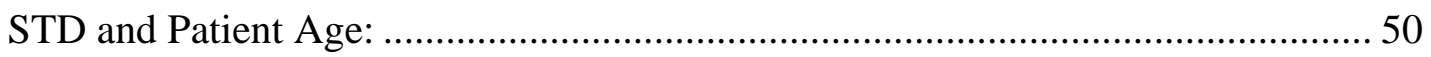

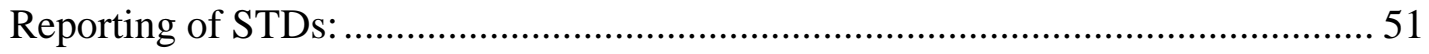

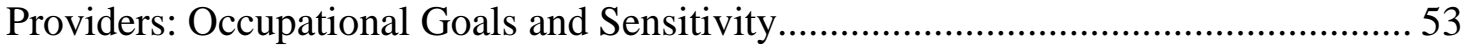

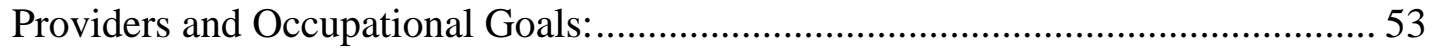

Years in Practice, Experience, and Sensitivity: .................................................. 55

Low-Income Populations and Policies Providers' Advocate...................................... 58

Issues Involved in Access to Care for Low-Income Populations: ........................... 58

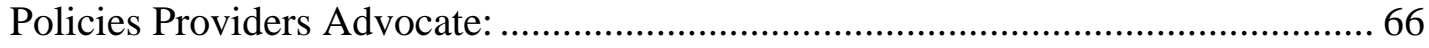

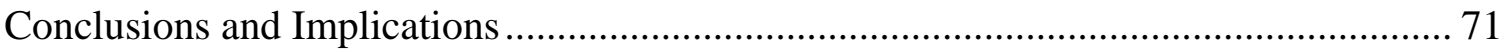

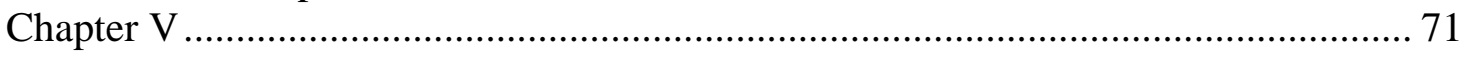

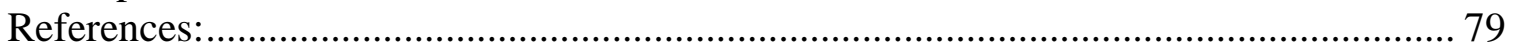

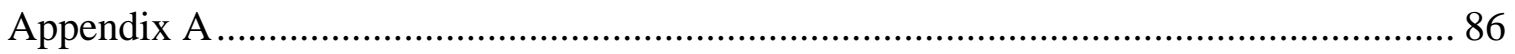

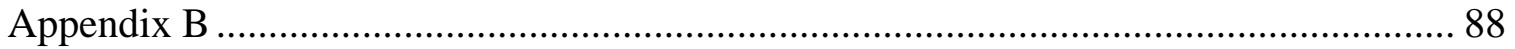




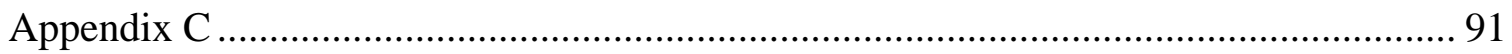

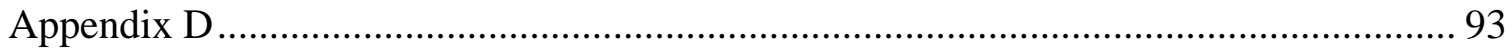

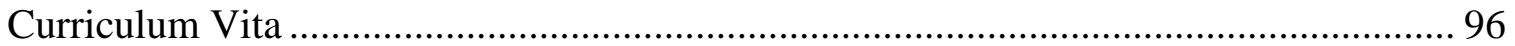




\section{List of Figures}

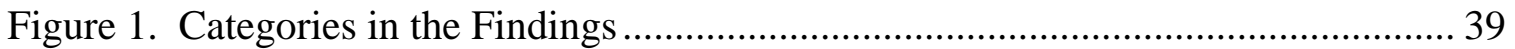




\section{List of Tables}

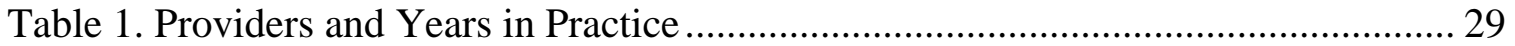

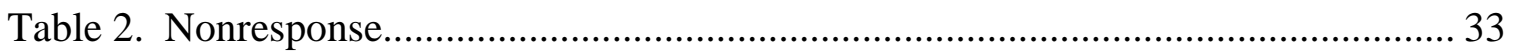




\section{Introduction}

\section{Chapter I}

Each year, more than 15 million new cases of sexually transmitted disease (STD) are diagnosed. Many of these diseases are incurable. Currently, 65 million people live with an incurable STD in the United States (Centers for Disease Control and Prevention [CDC] 2000). Sexually transmitted diseases (STDs) and reproductive tract infections in women can lead to infertility and sometimes death (CDC 2004a). They also entail a high level of emotional and physical discomfort. One of the causes of this emotional discomfort is the negative stigma attached to having an STD. The characteristics that our society associates with having an STD are "indiscriminate promiscuity, pollution, and uncleanness” (Lawless, Kippax, and Crawford 1996:1371). Nack (2002) found that lowincome women with STDs have been particularly stigmatized because they have been defined historically as transmitting STDs to wealthier classes.

Health care providers’ attitudes towards STDs and low-income populations can add to this stigma. O’Connell (1997) found the need for providers to be more sensitive when dealing with patients. She researched female patients whose providers asked questions like “OK, let’s see what kind of crud you're growing,” and "Does your husband fool around?” She found that invasive, insensitive questions like these from providers can further stigmatize patients and prevent them from receiving care in the future. O’Connell (1997) stresses the importance of keeping practitioners from imposing values on patients. She found that many practitioners believed that only promiscuous women were at risk for STDs and consequently sometimes do not test the necessary populations for STDs. This assumption can result in a higher number of untreated diseases. Provider attitudes like the 
ones O’Connell (1997) found may potentially prevent women from seeking treatment or talking to their providers about STDs.

This study and other studies (Beatty et. al. 2003, Danielson et. al. 1999, Family Practice Management 1999) look at provider attitudes in urban environments or close to urban environments. Do health care providers who consistently deal with low-income populations with STDs in rural settings view patients negatively or treat them similarly to the way O’Connell (1997) found? My research at Initiative Health and Ridge Clinic in the rural state of West Virginia will attempt to answer this question. ${ }^{1}$

Other research questions associated with my study include: What do Health Care Providers (HCPs) at Initiative Health (IH) and Ridge Clinic (RC) see their roles as? Do HCPs think a patient's self-identity is changed by receiving an STD diagnosis? Are STDs reported thoroughly and often? What are the recurring issues HCPs deal with in the treatment and diagnosis of low-income women with STDs? What are the steps HCPs take when diagnosing a low-income woman with an STD? Do HCPs think this process can be improved to better suit their patients and themselves? What policies would HCPs like to see implemented to help them accomplish their jobs better? What are the goals of HCPs in an environment like West Virginia?

Grounded theory is defined as when "the researcher attempts to derive a general, abstract theory of a process, action, or interaction grounded in the views of participants" (Creswell 2003:14). The purpose of my grounded theory research is to better understand the attitudes and perspectives of providers in a small community-based and publiclyfunded atmosphere. I used grounded theory and dimensional data analysis methodology.

\footnotetext{
${ }^{1}$ Both clinic titles have been changed to protect identities. Names of providers have also been changed to respect their privacy.
} 
The providers in my study diagnose low-income women with STDs on an almost daily basis $^{2}$. Providers are the accessible link between patients and the researchers. I interviewed 19 health care providers (with one interview not included in the findings), including certified nurse practitioners, registered nurses, a physician’s assistant, a sexually transmitted infections educator, certified nurse midwives, and physicians, who give "free" or reduced-cost reproductive and sexual health care to young poor women in West Virginia. The research was conducted at two confidential locations concurrently. One of these locations is publicly-funded, while the other serves mainly young people who are at-risk for not having health insurance. My study encompasses providers who specialize in many different areas of general, family, women's health, and internal medicine. This broad spectrum of providers is important to try and understand as many perspectives as possible that are associated with sexual and reproductive health care.

The Health Information Portability and Accountability Act (HIPAA) makes it extremely difficult to interview patients directly about their experiences with providers. In order to comply with HIPAA, I must get an authorization from all research subjects prior to the intended use or external disclosure of protected health information (PHI) and a consent and authorization form. It is possible to obtain an exemption for the authorization form, but in the case of research about sexually transmitted disease and atrisk populations (people with lower education levels etc.), it would be difficult. In order to receive a wavier, the research could not practicably be conducted without the waiver. And all situations where I could interview patients, I would have adequate opportunities

\footnotetext{
${ }^{2}$ Low-income is defined as less than 200\% of poverty, or \$30,520 for a family of three in 2003 (Henry Kaiser Family Foundation 2004c).
} 
for the participants to sign a wavier. My research would therefore not be eligible for exemption from an institutional review board.

Because of logistical reasons like these involved in Institutional Review Boards, HIPAA regulations, and personal ethical reasons, I have chosen to interview providers. Interviewing providers and not patients might not give adequate voice to the patients since they are seen through some one else's eyes. However, I see this as a better option than infringing on a patient's privacy by talking directly to them in an exam situation. Personally, I would also not feel comfortable being involved in research that I felt was too voyeuristic. STDs are a sensitive subject for patients and I would not feel comfortable being in the room and interviewing them directly during physical exams.

One reason research in a publicly-funded clinic is important is because most women receive their STD testing and treatment from public clinics. Nearly $25 \%$ of women who received any contraceptive care and nearly one in three women who received STD testing and treatment, visited a publicly funded family planning clinic in 1995 (Frost 2001). It is important to understand provider attitudes in clinic settings such as these because they are the concentrated locations where low-income and uninsured women receive their sexual and reproductive health care. Frost (2001) also found that Medicaid recipients and uninsured women were three to four times more likely to obtain care from a publicly-funded clinic than women with private health insurance. The majority of these women who used public clinics were young, minorities, unmarried, poor, and less-insured (Frost 2001). Since my research will look at providers who deal with low-income populations, publicly funded clinics are the best place for my research. 
Almost half of women, ages 18-49 have never discussed STDs with their provider. One of the most commonly cited reasons for this was "embarrassment or concern about being judged” (Ascribe 2003:1). Patients also place a high importance on provider traits when seeking a place of treatment. African American adolescents in San Francisco, California place a higher priority on provider traits than any other issue regarding clinics where they might be treated for an STD (Family Practice Management 1999). Another study by Linnehan and Groce (1999) looks at patients with HPV and cites the need for more research to be done on provider attitudes. They document the need for more provider sensitivity when dealing with young women with STDs. They agree that the overwhelming majority of health care providers see HPV infection as a major health problem for young women, "but only 54\% spend at least 10 minutes providing education and counseling to all of their HPV patients” (Linnehan and Groce 1999:137). The attitude of providers are important to patients and as such, should be studied more indepth.

Women bear the largest burden of STDs, suffering more serious and frequent complications than men (CDC 2000). Characteristics of female genitalia expose women to many potential problems from STDs that men are less likely to encounter. Women are much more likely to have pressing symptoms and complications because of physiological reasons (CDC 2004a). Poor women and women without health insurance have a far more difficult time accessing sexual and reproductive health care than higher income women (Wyn, Ojeda, Ranji, and Salfanicoff 2004). Women of any income bracket are much less likely to be insured through job-based coverage (Henry Kaiser Family Foundation 2004c). As a result, it can be much more difficult for a single female parent or a female 
head of household to adequately gain health insurance for herself and her family. Frequently, low-income patients or people without health insurance put off seeing a doctor because they cannot afford care. Because of these reasons, it is important to study locations where health care providers treat mostly low-income women without health insurance. Targeting these locations in my research leads to a greater understanding of providers who deal with populations who have the most difficultly accessing treatment of their STDs.

Publicly-funded clinics benefit poor uninsured women living in rural areas by providing Pap tests (a test that involves microscopic examination of cells collected from the cervix, used to detect changes that may be cancer or may lead to cancer, and to show noncancerous conditions, such as infection or inflammation [University of Chicago Hospitals 2005]) and STD screening. Some types of human papillomavirus (HPV) cause cervical cancer. About $75 \%$ of the reproductive-age population has HPV, with the majority occurring in women under age 25 (CDC 2004). A large number of women do not have regular Pap tests, which help to screen for HPV. The majority of these women are older, uninsured, minority, poor, and live rural areas (Agency for Health Care Research 2003).

West Virginia is ranked number 42 for women having Pap Smears. This ranking implies that 41 states had better access to services than West Virginia (Henry Kaiser Family Foundation 2004b). Even though the majority of women who do not receive regular Pap tests are older, younger women are much less likely than older women to not have health insurance. Being uninsured is a significant barrier to regular and consistent reproductive and sexual healthcare (Wyn et. al. 2004). The vast majority of women who 
have the most problems accessing services are either very old or very young; the two most at-risk populations for needing care.

One-third of low-income women in the United States lack health insurance coverage (Wyn et.al. 2004). Most poor people in the United States, and half of our working poor, do not have health insurance which can make accessing sexual and reproductive health care difficult. About $16.6 \%$ of West Virginia's population does not have health insurance. Many low-income people in West Virginia receive their health insurance from Medicaid (Hoffman and Wang 2003). High rates of Medicaid coverage are related to high levels of poverty in West Virginia. Also, women with Medicaid are more likely to report being in poor health than women with private insurance and are more dissatisfied with their quality of care than privately insured women (Wyn et. al. 2004). About 35\% of low-income women in West Virginia do not have health insurance (Henry Kaiser Family Foundation 2004c).

There is a great deal of research dedicated to women's reproductive and sexual health care (e.g. de Bruyn 2004; Haslegrave 2004; Singh et. al. 2001; Skouy 2004; Wortmann 2003). However, most of the existing literature on this topic points out problems in developing countries in which women have trouble accessing reproductive and sexual health care services. The literature that is dedicated solely to the United States is mainly about accessing family planning services and birth control, with little research devoted to provider attitudes. This research also largely ignores rural settings. Research on women's reproductive health and the above cited literature highlights the need for more research to be done on provider attitudes towards young, uninsured populations and sexually transmitted disease. There is some literature on sexually transmitted disease and 
stigma, but much of it is about HIV/AIDS. Often, studies dedicated to stigma (e.g. Chesson et. al. 2004, CDC 2000) do not include poor rural women and typically omit qualitative research about provider's perspectives. Provider attitudes are important to patients receiving sexual and reproductive health care (Family Practice Management 1999) and as such should be studied more in-depth. My research begins to fill in this gap. 


\section{Literature Review}

\section{Chapter II}

In order to understand health care provider attitudes towards low-income populations with STDs in West Virginia, it is helpful to know the incidence and prevalence of STDs and to understand the issues surrounding sexual and reproductive health care. The literature review begins broadly with information directly related to STDs and progresses to issues surrounding health care providers.

\section{Sexually Transmitted Disease/Sexually Transmitted Infection}

Rates of many sexually transmitted diseases in the United States are high and continue to increase (CDC 2000). STDs disproportionately affect young people, with 1524 year-olds making up $48 \%$ of the new cases of STDs (Weinstock, Berman, and Cates Jr. 2004). An estimated 18.9 million new cases of STDs were diagnosed in this age group alone in 2000 (Weinstock, Berman, and Cates Jr. 2004) and cost \$6.5 billion to treat (Chesson, Blandford, Gift, Tao, and Irwin 2004). The cost illustrates the many potential savings that could be achieved through better prevention activities and better access to sexual health care.

The high rates of STDs may be due to difficulties accessing health care and are correlated with a high rate of poverty (CDC 2004a). Of the number of Americans with STDs, women are more likely than men to contract STDs and also to bear the worst consequences (CDC 2004a). If untreated, up to 40\% of women infected with gonorrhea and chlamydia may develop pelvic inflammatory disease (PID), which can lead to infertility and even death (CDC 2004a). Approximately half of gonorrhea infections and $70 \%$ of chlamydial infections are asymptomatic. Thus people often do not realize they 
have an STD and may pass it on to others without receiving treatment (CDC 2004a). Because of this, frequent STD testing is important for both men's and women's health. Certain STDs, such as human papillomavirus (HPV) and herpes simplex virus (HSV), are more prevalent in young women than men. Almost 75 percent of the reproductive-age population has been infected with HPV and between 28 and 46 percent of women under the age of 25 have been infected (CDC 2004a). This statistic only includes the reported cases of HPV. HPV, in particular, can cause more lasting and difficult complications in women (Weinstock, Berman, and Cate Jr. 2004) because of HPV's link with cervical cancer. It has been identified as the main causal agent in over 95\% of cervical cancers (Beatty, O’Connell, Ashikaga, and Cooper 2003). Young women have an increased risk for developing HPV infection (Linnehan and Groce 1999). Almost half of young women (with a mean age of 20-22) seen in college health centers may harbor HPV (Linnehan and Groce 1999).

Herpes (HSV) is also more common in women than men (CDC 2004a). There are approximately 45 million Americans living with HSV (Alexander, LaRosa, and Bader 2001) and HSV disproportionally affects women. It affects one out of four women versus one out of five men (CDC 2004). One of the reasons for this discrepancy is because male-to-female transmission is more efficient (CDC 2004). When looking at STD rates like these, researchers should be aware that the actual rates are probably much higher. Studies like these show the need for more research related to women and sexual healthcare because they stress the actual high rates of STD transmission in women. 


\section{Sexually Transmitted Disease and Stigma}

In addition to their cost and incidence among young women, STDs are also mentally taxing and have a negative societal stigma associated with them. Lichtenstein (2003) studied this stigma and found that the high rate of sexually transmitted infections (STIs) in the southern United States was influenced by the stigma surrounding STIs. Four dimensions of stigma emerged from her research. First, religious ideals influenced how health care providers felt about "promiscuous" patients, especially women. Second, many patients feared that their confidentiality would be compromised if they were seen at local clinics. Third, certain racial attitudes affected a patient's willingness to be treated for an STI. Fourth, patients did not want to know they had the STD because they would be “scarlet lettered” for life. She calls this concept “stigma transference” (Lichtenstein 2003). All of these stigma-related factors prevented patients from seeking screening and treatment for STIs or STDs. Stigma is a significant barrier to treatment for many people. Goffman (1963) was one of the first researchers to do research on stigma. His book, Stigma: Notes on the Management of Spoiled Identity, inspired social scientists to examine stigma among many groups of people (Bower 2001). According to Bower, any trait that marks the bearer as unacceptable in a specific society creates a spoiled identity (Bower 2001). Fortenberry et. al. (2002:2) defines stigma as "an attribute or label that sets a person apart from others and links the labeled person to undesirable characteristics.” Fortenberry et. al. (2002) conducted face-to-face interviews with approximately 2,000 participants who were recruited from community-based clinics in seven cities to answer questions about stigma and shame related to STDs. They found that individuals who had received a gonorrhea test in the past year felt less shame than those who had not been tested. In other words, testing for STDs not only informs patients 
who needs treatment, it also helps to alleviate stigma surrounding STDs in general. They note that the stigma associated with STDs is not likely to decrease without education efforts and that stigma is a major barrier to appropriate sexual health care (Fortenberry et al. 2002).

Nack (2002) also studies stigma and asserts that public opinion has historically targeted low-income women and stigmatized them as being vessels of disease, especially venereal disease. She also argues that public health efforts in diagnoses must address the prevalence of a gendered double standard in the existing sexual ideology (Nack, 2002: 481). This gendered double standard is evident in current United States medical practices (Rosser 1994).

\section{Women's Health and Gender}

Rosser (1994) argues that using feminist theories and methodologies in medical research and health care issues is crucial to the health of the nation. She believes feminist theories can help to alleviate this gendered double standard. Medical and clinical research practices have historically been male-biased (Rosser 1994). Frequently, medical studies and clinical trials have been done only on the white heterosexual male, who generally represents the standard of health (Spongberg 1997). Studying only men can produce cures and remedies that are not always appropriate for women.

Men have also been viewed as more robust and physically fit than women. Women who have health problems are often seen as complainers. For example, Nechas and Foley (1994) found that when female patients are treated for a disease, such as cardiovascular disease, they are much more likely then men to be dismissed as healthy

because it is often believed by practitioners that the disease is all in their head. Since the 
female body has been viewed historically as contaminated (Spongberg 1997),

androcentric studies like these and other male-centered medical practices are ideological challenges when treating women with sexually transmitted diseases. Additionally, men also receive more thorough care (Nechas and Foley 1994). This trend is even more pronounced among minority women and poor women where death rates from heart disease are twice as high for African Americans than for white women. Poor rural women are also more likely to be in worse health than their more economically sound counterparts (Nechas and Foley 1994).

\section{Socioeconomic Status, Health Insurance, and West Virginia}

Socioeconomic status (SES) is a strong predictor of health status (Adler and Coriell 1997). Adler and Coriell (1997) found that as SES rises, mortality decreases and that as level of education increases for women, mortality also decreases. They also found that HIV infection is more prevalent in low-income households. In short, the poorer a person, the worse health he or she generally has.

West Virginia is a poor state and only four states (Louisiana, Arkansas, Mississippi, and New Mexico) and the District of Columbia ranked lower than West Virginia, on average, from 2000-2002 in the percentage of people living in poverty (Proctor and Dalaker 2003). For the second consecutive year, poverty rates grew in West Virginia from 2000-2002 (Proctor and Dalaker 2003). Poverty and SES affects a person’s access to care (Singh et. al. 2001), but it also affects whether or not he or she will have health insurance.

People living in or at near poverty levels are less likely to be able to afford private health insurance if their employer does not provide health insurance (Wyn et. al 
2004). Having health insurance is a large predicator of whether or not a person will have access to care (Pamuk, Heck, Reuben, and Lochner 1998). Persons without health insurance are more likely to report an unmet need for care and are less likely to receive preventive health services (Pamuk et. al. 1998). Starfield and Shi (2004) found that having health insurance is very important, but the notion that health insurance equals access to health care has become ingrained, despite abundant literature that proves otherwise. Health insurance is not always an adequate predictor of quality care, although it is important in facilitating health care use overall. They found that other factors, such as having a consistent primary care provider or having private insurance versus Medicaid, are just as important as having health insurance.

Medicaid and Medicare are health insurance programs sponsored by the United States government for the poor and elderly. However, these programs have their own distinctive problems. Even with Medicaid providing insurance for poor people, 30\% of poor people had no health insurance of any kind in 2000 (Waldrop 2000). Waldrop (2000) found that $48 \%$ of poor, fulltime workers were uninsured in 2000 and that $27 \%$ of young adults aged 18-24 in any economic bracket, were uninsured in 2000. Medicaid covers only 1 in 5 low-income women and those women who are on Medicaid are dissatisfied with their quality of care (Wyn, Ojeda, Ranji, and Salganicoff 2004). In West Virginia, $17.7 \%$ of its coverage insurance coverage comes from Medicaid versus $11.7 \%$ of the coverage in the United States (Hoffman and Wang 2003). This trend reflects West Virginia's higher level of poverty.

Poor women in West Virginia are particularly at risk for not having health insurance. Twenty-one percent of women in West Virginia and 35.5\% of low-income 
women in West Virginia do not have health insurance (Henry Kaiser Family Foundation 2004c). The Kaiser Family Foundation (2004c) also found that women who work are much less likely than men who work to be eligible for their employer's health plan. This is one reason why more women are uninsured than men. In addition, women generally have lower incomes and have a greater need for services throughout their lives due to pregnancy and other reproductive health care factors. Because of these issues, the growth in health care costs has had a disproportionate effect on women (Kaiser Family Foundation 2004c).

\section{Access to Care and Socioeconomic Status}

Low-income women experience significant disadvantages in accessing reproductive and sexual health care coverage (Wortmann 2003). Medicaid recipients and uninsured women are three to four times more likely to obtain care from a publiclyfunded clinic than women with private health insurance (Frost 2001). The women who most depend on publicly-funded clinics are young, minority, unmarried, poor, and lessinsured women (Frost 2001). One in three women who received STD testing and treatment visited a publicly-funded clinic in 2000 (Frost 2001). Because of the large number of women who use publicly-funded or "free" clinics, it is important to do research related to low-income women with STDs in places which service them the most.

Frequent and easy access to publicly-funded clinics can be difficult when looking at factors such as transportation, availability of clinic appointments, cost barriers, and child care (Wyn et. al. 2004). These factors can contribute to low-income women lacking a usual and consistent source of care. Almost one-half of low-income uninsured women lack a usual source of care (Wyn et. al. 2004). Lacking a usual source of care contributes 
to women not receiving regular Pap tests and mammograms (Wyn et. al. 2004). Breast cancer, which is dectected by mammograms, is the most commonly diagnosed cancer in women in the United States and can be influenced by factors such as SES (Breast and Cervical Cancer Research Highlights 2003). Cervical cancer is another commonly diagnosed cancer. In 2002, it is estimated that there were 13,000 cases of diagnosed invasive cervical cancer (Breast and Cervical Cancer Research Highlights 2003). Cervical cancer is in the top three most common cancers worldwide and can be caused by HPV. It is easily detectable in its early stages by a Pap test. However, "many women still do not have regular Pap tests, particularly older women, uninsured women, minorities, poor women, and women living in rural areas” (Breast and Cervical Cancer Research Highlights, 2003:2).

In West Virginia, only 84\% of women report having had a Pap smear within the last three years (Henry J. Kaiser Family Foundation, 2004). Thus 16\% of women that should be having annual Pap tests are not receiving the care they need in West Virginia. West Virginia is ranked 42 out of the 50 states for women having Pap Smears (Kaiser Family Foundation, 2004). Women in 41 states have better access to reproductive health services than West Virginia.

Better access to reproductive and sexual health services can help to decrease adolescent pregnancy rates. Singh, Darroch, and Frost (2001) found that adolescent childbearing was more likely to happen when women were of low-income status and poorly educated. Singh et. al. (2001) studied the reproductive behavior of women in four developed countries (Canada, Sweden, France, and Great Britain) and compared the findings with the United States. They found large differences in the behavior between 
teens in the United States and teens in the other developing countries. In the United States, regardless of socioeconomic status, women are the most likely of the five countries to give birth as adolescents (Singh et. al. 2001). The United States ranks $44^{\text {th }}$ out of 45 industrialized countries for its very high adolescent pregnancy rate (Wortmann 2003). Singh et. al (2001) theorized that this large difference was due to the higher population of disadvantaged adolescents in the United States than in other developed countries (Singh et. al. 2001). They define disadvantage as have low levels of education, living in poverty, living in a single-parent household or in an economically struggling neighborhood, having poorly educated parents, and lacking educational and job opportunities (Singh et. al. 2001). There are some researchers who have speculated why adolescents in other developed countries are less likely to acquire an STD or have fewer pregnancies. The researchers suggest that the reason for this is better sexuality education, a larger societal openness regarding sexuality, and better access to reproductive health services (Singh et. al. 2001). In other words, adolescents in the United States have a much higher rate of unprotected sex and have a more difficult time accessing reproductive services.

\section{Perceptions of Health Care Providers}

The views of health care providers who screen and treat people with STDs can have a large impact on the perceived quality of reproductive health care services. Women often do not speak about STDs with their providers because of the stigma attached to having an STD (Ascribe 2003). Lichtenstein (2003) found that this stigma prevented patients from prevention and treatment services. This stigma was related to how health care providers felt about “promiscuous” patients and especially women. A provider’s 
views and behavior are very important to a patient. A study from the University of California at San Francisco found that African American adolescents place a higher priority on provider traits than they do on any other issue regarding the clinic where they would be treated for an STD. Waiting room lines and convenient hours were rated second in importance to the attributes of health care providers (Family Practice Management, 1999). Thus, young people are more concerned with their provider's attitudes, clear explanations, and answering of patient questions than they are with the place at which they are being treated. However, some research [Nack (2001), O’Connell (1997), Linnehan and Groce (1999)] shows that providers are not always being sensitive with their patients.

Linnehan and Groce (1999) found that although the vast majority of providers agree that HPV infection carries a large burden of psychosocial effects, only $54 \%$ of providers spend at least 10 minutes supplying counseling and education to their patients. The providers in the study didn't take the time to be informative and kind while giving a HPV diagnosis. Providers need to improve the content of counseling and education surrounding the disease (Linnehan and Groce 1999). Nack (2001) also documents the need for more provider sensitivity during the initial diagnoses and subsequent treatment sessions. After interviewing women about their treatment experiences being diagnosed with HPV and HSV, she found that women tend to feel dirty and immoral after having negative experiences with providers during the diagnostic phase.

Sensitive communication between a provider and patient can produce a more pleasant experience during the diagnostic phase, but it could also persuade more women to be tested for STDs. O'Connell (1997) found that the most at-risk women for STDs are 
not getting tested as often as they should because providers sometimes hold beliefs that may anger clients and keep them from inquiring about STD testing and treatment. For example, some providers think that only immoral women get STDs or ask questions using insensitive language such as “Does your husband fool around?” She found that invasive, insensitive questions like these from a provider can further stigmatize a patient and prevent them from receiving care in the future. O’Connell (1997) asserts that practitioners should refrain from imposing value systems like these on clients.

Another factor that might prevent women from receiving treatment is that women are often afraid of being judged by their health care provider. Ascribe reported on a survey conducted by the Henry J. Kaiser Family Foundation and SELF magazine and found that misperceptions and perpetuating stereotypes about STDs are preventing women from talking to their health care providers about their sexual health (Ascribe 2003). Almost half of women, ages 18-49 have never discussed STDs with their provider. One of the most commonly reasons cited for women not to speak to their providers was “embarrassment or concern about being judged” (Ascribe, 2003:2). Because of the stigma surrounding STDs, women are afraid to speak to their health care provider and four in five women “underestimate or simply don't know the rates of STD infection in this country" (Ascribe, 2003:1). If the stigma surrounding STDs was not so socially distinct, STD rates might be lower. The rates would be lower due to increased awareness and women would be more likely to speak to their health care provider about STDs. Open communication between the provider and the patient helps to decrease STD risk (O’Connell 1997). 
All of this literature suggests that young women are more likely to contract an STD than men, that young poor women are less likely to have health insurance which facilitates better access to sexual and reproductive services, that low-income women are more likely to be in poor health, that most poor women have no health insurance despite programs like Medicaid, and that there is a need for young low-income women to have consistent and sensitive care from their health care providers. The literature shows a need for more research to be done on provider's attitudes and practices when diagnosing low-income women with STDs in a publicly-funded clinic because most poor young women visit publiclyfunded clinics for their sexual and reproductive health care needs. Furthermore, more research needs to be done in a rural state like West Virginia where there are high numbers of uninsured low-income women. 


\section{Procedures and Methods}

\section{Chapter III}

\section{Qualitative Research Design}

A qualitative research method is appropriate for this specific study in ways that quantitative research is not. Because qualitative research takes place in the natural setting, I have been able to observe a high level of detail firsthand and have been highly involved in the actual participant experiences. I have been able to see their facial and bodily reactions to the questions and share more in the experience of what they were telling me. For example, if I were to conduct a survey and then analyze it quantitatively, I would not be able to see physical reactions to the question "How many years have you been involved in women's reproductive health care?” On a survey the respondent might simply list the number of years, but in an interview situation I can observe the participant and see if he or she has a look of pride or disgust on their face when describing how many years they have been involved in health care. If the tone of voice includes sarcasm, an excerpt from an interview has a very different meaning that the researcher can be pick by being in the interview situation.

The interviews were conducted on site at participants' offices in several departments of Ridge Clinic (RC) and at Initiative Health (IH) [the names have been changed to protect privacy]. Conducting interviews at the participants’ places of employment allowed the participants to feel more comfortable with the interview process. Conducting interviews is more "interactive and humanistic” (Creswell 2003:181) than having a participant fill out a questionnaire. My interviews were semi-structured, but leaned more towards structured interviews since I came into the interview situation with a 
list of specific questions. Interviewing health care providers in semi-structured interviews allowed participants to feel free to expound on questions. Using a semi-structured interview scenario leaning towards more structure helped participants to feel more comfortable. Oftentimes, participants will feel uncomfortable because they might think the pressure to have a meaningful interview is on them. Going into the interview situation with a list of questions (while leaving room for participants to add anything they want) helps to move the interview along. Providers have tight time schedules so it was important to keep moving. However, I also left room for flexibility in case providers had more to say. This semi-structured flexibility added depth to my data. It allowed providers to be able to ask questions of me when they needed clarification of what I was asking them. Qualitative interview techniques allowed me to create a comfortable dialogue between myself and the participants. This contact is not found in survey research.

I chose the questions I posed to health care providers based on current research. Much of the current research suggests that providers need to be more sensitive when dealing with patients (O’Connell 1997) so I chose questions that could reveal whether or not providers were being sensitive. I asked how providers saw their job. If they saw their job in a negative light, it could affect patient care. I asked how much time was spent giving diagnoses because a very small amount of time could indicate less counseling time with the patient leaving with unanswered questions. Much of the literature suggests that low-income women have a more difficult time accessing reproductive health care (Wyn et. al. 2004) so I wanted to ask providers what factors they felt affected low-income women receiving care. Some literature suggests that STDs change a patient's self-image 
in a negative way (Nack 2002), so I asked providers if they had ever witnessed any negative reactions to their STD diagnoses.

\section{Role of Researcher}

It is important to note any biases of the researcher before explaining a study’s findings. Who a person is colors and shapes their interactions in life and in research settings. In my case, I have certain starting biases that probably influenced my findings and why I even chose this topic to study in the first place. When I first moved to this region, I was a patient at IH. I had no health insurance, but was still in need of reproductive health care. I participated in their family planning clinic and found their services to be wonderful. These services would have cost me close to $\$ 500$ without health insurance, but I received them for free. The providers were extremely pleasant, wonderful to be around, and did not make me feel badly that I couldn't afford to pay them.

My findings could be impacted in a personal way because I liked IH so much. I was prompted to do this study because much of the existing literature cited the need for more provider sensitivity and I did not find this to be true. Because of my emotional connection to my research, my data and results could be skewed. I tried as much as possible to extricate myself from the situation, but it is impossible to be totally unbiased in research. It is worth noting that my personal background and the way I come across could have affected how providers spoke to me; both when I was a patient and when I was a researcher. I am white, well spoken, and come across as from an upper middle class background. If I was not as similar to them, I could have gotten much different results. My status, privileges, and educational level could have shaped how I saw IH and RC and how they saw me. My results could also be skewed since I started with the 
assertion that more provider empathy was needed during diagnostic phases as the literature suggested, even though I did not personally feel this way based on my own experience.

My role as the researcher was particularly important in the process of data analysis described below because dimensionality calls for "an inquiry into its parts, attributes, interconnections, context, processes, and implications” (Schatzman 1991:309) in the “story.” I used my past experiences with IH and friends' experiences to inform the context of how I developed my research and interview questions. This bias of favorable feeling towards IH from being a patient gave me a unique perspective to begin my research.

\section{Dimensional Analysis and Grounded Theory Research Strategy}

My study employed a grounded theory research design with some techniques

from dimensional analysis to derive themes and conclusions from participant interviews. Dimensional analysis is based on Glaser and Strauss’ (1967) model for grounded theory research with small variations. According to Charmaz (2003) grounded theory helped to defend qualitative methods in a time in social science history when quantitative research constituted the dominant approach. As I have stated earlier, grounded theory is defined as when "the researcher attempts to derive a general, abstract theory of a process, action, or interaction grounded in the views of participants” (Creswell 2003:14). The grounded theory approach gives researchers guidelines that help to build theoretical frameworks, but do not specifically detail data collection techniques (Charmaz 2003). This approach allows the researcher to move with each step of the research and develop concepts without putting a starting value or bias on which procedures to use. Using the grounded 
theory approach during my data analysis phase allowed for concepts and recurring themes to begin to show during the collection process. As I conducted more interviews, I could see patterns emerging that I would not have been able to see employing another analysis technique. For every interview I tried to adhere to my list of developed questions. However, appropriate questions were sometimes added during the interview process. This is consistent with the emergent nature of grounded theory.

I began the analysis by using open coding. I used suggested techniques from Strauss and Corbin (1998) who revised earlier procedures for the development of grounded theory. Open coding is a line-by-line analysis in the text of the transcriptions from my interviews (Strauss and Corbin 1998). I labeled these concepts, phenomenon, or actions with such titles as "protocol assent” or "provider frustration.” I then compared incident to incident as is consistent with Strauss and Corbin's (1998) methods. These codes were continually fine-tuned in order to make the best possible representations. I used handwritten memos during this process. I constantly compared and cross-referenced the codes and memos and categories began to take shape. I gradually developed a story with theoretical undertones from the emergent patterns in my participants' responses by finding these categories and then subcategories within the data. A list of categories and subcategories are included in the appendix.

The second step in my coding process was axial coding. Axial coding continues the process begun in open coding, but links categories to levels of dimensions. In axial coding, the paradigm model is used to establish relationships between conditions, phenomena, and interactions (Strauss and Corbin 1998). Categories are also levels of phenomena. The conditions inherent in the categories of my data lead to situations that 
can be strung together with actions and interactions found with the emerging conceptual matrix of what health care providers disclosed. Basically, the stories providers told me were grouped into different categories and came to represent an overall theoretical picture. Strategic interactions shape phenomenon (Strauss and Corbin 1998). In my research, an example of a strategic interaction would be a nurse practitioner who told a married patient who had signs of trichomoniasis to come back for further examination. Not only did the nurse practitioner do so in order to be sure the woman was correctly diagnosed, she did so to give the woman time to digest the social implications of infidelity.

My themes, categories, subcategories, and dimensions of experience were related to the interview questions and to patterns of themes that health care providers brought up during our interview sessions. Categories depict issues important to matters that are being studied and subcategories deal with the why and how of the phenomenon being looked at (Strauss and Corbin 1998). Dimensions of experience are the term from Schatzman’s (1991) theoretical framework for utilizing grounded theory that represents the processes, contexts, or conditions of concepts being studied grounded in the data (Schatzman 1991). Dimensions of experience encompass all the issues surrounding concepts emerging from the data. In the case of my research, all the issues surrounding a low-income woman's access to care develop into a framework similar to the selective coding process highlighted by Strauss and Corbin (1998). The dimensions of experience encompass the issues within subcategories in my research. Strauss and Corbin (1998) use the term selective coding to describe the integration and formation of theory from the data. Selective coding constitutes the last step in the three step coding process (Mellion and 
Tovin 2002). Instead of using strictly selective coding, I used the dimensions of experience to help create the theory and complete the analysis process.

\section{$\underline{\text { 1. Sample Selection }}$}

I sought out sites where providers worked mainly with low-income populations, and particularly women, with sexually transmitted diseases. Theoretical sampling in grounded theory is driven by concepts taken from the evolving theory. It is defined as data gathering and is based on comparing concept to concept (Strauss and Corbin 1998). The sampling technique employed was purposeful sampling, a term used interchangeable with theoretical sampling by qualitative research. The difference between theoretical sampling and purposeful sampling is that purposeful sampling involves a deliberate decision to sample from a particular area (Cutcliffe 2000). I chose physicians specifically for their practice specialties. I looked through specialties of physicians and researched who dealt with sexual and reproductive health care on a daily basis and contacted them via email, phone, letters, and in person. Participants were selected from two main clinics who offer free and reduced cost health care to low-income populations.

\section{Research Site Choices:}

There are a few different reasons why I choose to interview providers at IH and RC. First of all, IH offers the most comprehensive family planning and STD services for the low-income population in their region. The other places that offer free or reduced cost healthcare in West Virginia deal primarily in other health areas besides sexual and reproductive health. Since STDs affect women more than men (CDC 2004a) and younger women more often than older women (Weinstock, Berman, and Cates Jr. 2004), it makes sense to interview providers where young low-income women go for sexual and 
reproductive health care. The family planning clinics at IH are almost solely female and usually deal with women under 30 years of age who are low-income.

I choose to interview providers at RC because they provide services for young people who may or may not have health insurance on a daily basis. Young sexually active people are more likely to get STDs (Weinstock, Berman, and Cates Jr. 2004), so I chose a second research site that dealt mainly with younger patients. I also choose these places because they are in close geographical proximity to one another, yet are different enough to compare and contrast the treatment methods of providers. However, during the analysis phase the comparisons between the research sites were not significant enough to analyze. Their comparison was compounded by the fact that many providers work for combinations of RC and IH. The lack of identifiable comparison proved to be positive because I found many providers telling similar stories and having similar views of their occupations. These similarities lead to greater internal reliability.

\section{Participants}

Eighteen health care providers participated in semi-structured interviews. Three registered nurses, a physician assistant, seven physicians, one sexually transmitted infections educator, four nurse practitioners, and two nurse midwives participated in the interviews. The interviews ranged from 25-50 minutes in length. There were 13 females and five males. The interview questions are included in the appendix of the thesis. A background questionnaire was not employed because demographic questions pertinent to my study were included in the interview questions. The following table shows the sex of the providers interviews, their provider status, and the number of years that have worked in women's health care. 
Table 1. Providers and Years in Practice

\begin{tabular}{|l|l|l|l|}
\hline $\begin{array}{l}\text { Place of } \\
\text { Employment }\end{array}$ & Sex & $\begin{array}{l}\text { Number of Years in } \\
\text { Health }\end{array}$ & Provider Status \\
\hline $\begin{array}{l}\text { Initiative Health } \\
\text { (IH) }\end{array}$ & Female & 20 years & RN \\
\hline IH & Female & 13 years & RN \\
\hline IH & Female & 14 years & RN \\
\hline Ridge Clinic (RC) & Male & 12 years (only 5 as P-AC) & P-AC \\
\hline RC & Female & 17 years & $\begin{array}{l}\text { MS-STI } \\
\text { Educator }\end{array}$ \\
\hline RC & Female & 27 years (only 14 as FNP) & FNP \\
\hline RC & Female & 17 years & MD \\
\hline RC & Female & 33 years & CNM \\
\hline RC & Female & 19 years & MD \\
\hline RC & Male & 17 years & MD \\
\hline RC & Female & 6 years & CNM \\
\hline RC & Female & 23 years & WHNP \\
\hline IH, RC & Female & 20 years & CRNP \\
\hline IH, RC & Female & 27 years & WHNP, CNM \\
\hline IH, RC & Male & 21 years & MD \\
\hline IN, RC & Female & 16 years & MD \\
\hline IN, RC & Male & 24 years & MD \\
\hline IN, RC & Male & 21 years & MD \\
\hline
\end{tabular}

\section{Degree Abbreviations:}

$\mathrm{RN}$-Registered Nurse

P-AC-Physician's Assistant

MS-Master of Science

FNP_Family Nurse Practitioner

MD_Doctor of Medicine

CNM-Certified Nurse Midwife

CRNP_Certified Registered Nurse Practitioner

WHNP_-Women's Health Nurse Practitioner

Note: Some of these providers have additional degrees, but for purposes of anonymity I am not listing them. 


\section{$\underline{\text { 4. Contacting Participants }}$}

In 2004, my first step in contacting possible participants was to call Initiative Health (an organization who routinely gives reduced-cost or "free" health care to lowincome populations, but mainly serves women), explain my study, and ask to whom I should be directed. I was then transferred to a contact person, Maureen ${ }^{3}$, and I left a message about my intentions. She then called me back and I asked if it was possible to meet with her and explain my study. We set an appointment for two weeks from the initial phone call. I came to the appointment, but IH was extremely busy and Maureen did not have time to meet with me that day. However, I was able to leave a letter of intent and a list of the proposed questions. We rescheduled for a week later.

I attended the meeting a week later and Maureen had already asked her coworkers if they would participate in my study. They had agreed to participate and approved the questions. I let my contact person know that I would be emailing her in approximately one month to schedule interview appointments after I had IRB approval and my thesis prospectus approved. IH has four fulltime RNs, including Maureen, who work only for various health clinics such as the family planning clinics, and sexually transmitted disease screening clinics. IH also has two nurse practitioners that they contract with specifically for the family planning clinics. All of these providers agreed to participate and were included in the study. On occasion IH has a varying number of physicians from Ridge Clinic (RC) (an organization who deals with a younger patient population who often do not have health insurance) who volunteer their time during the family planning clinics and the STD clinics. I was able to interview the head of the STD clinics who also

\footnotetext{
${ }^{3}$ Her name has been changed to protect her identity.
} 
works for RC. Many of the providers whom I interviewed have spent time working for various other organizations involved in free or reduced cost general and reproductive health care that serve low-income populations.

The next step for contacting participants was to modify my existing contact letter for RC to obtain permission in order to interview their providers. I went in person and inquired as to whom I might speak with. I was shown to a room where coincidently many of the providers were together taking a short break from clinical appointments. I explained my study and immediately received consent from the providers in the room to be interviewed. I left my letter of intent with an administrative assistant who distributed the letter to potential participants. About two weeks later I received an email from the physician who is the director of RC with four names of providers who had agreed to be in my study.

After receiving approval from the Institutional Review Board for my study and receiving approval for my thesis prospectus from my committee, I emailed my contact person at IH in order to set up appointments. I also went in person to RC to set up appointments with the doctors who had already agreed to participate. I was able to schedule four interviews immediately with RC because at that particular time of year, they did not have a large quantity of patients. Setting up appointments at IH was more difficult. I received an email back from my contact person who listed each RN's individual phone number and the date I was to call them, (i.e. when they would be in their respective offices for scheduling). I called the nurses on the dates mentioned on the emails and scheduled appointments with each of them on different days. I tried to call my contact person, but she was not in the office and I left a message asking if she would 
return my phone call to schedule an interview time. In a week, after she had not returned my phone call, I called again and left another message. After waiting four days, I emailed her once again, but she did not reply. After interviewing the other three RNs and waiting another week I emailed her again, but she never replied to any of the phone messages or emails after agreeing to be interviewed the first time we met. I believe this nonresponse is due to this particular provider having a very busy and hectic schedule. I know that she wanted to participate in the study, but IH is a very demanding environment with a constant stream of patients who need care.

The two nurse practitioners who contract with IH had to be contacted separately. I simply emailed one of the nurse practitioners and she replied within a week that she would be willing to be interviewed. The other nurse practitioner was difficult to reach. I first emailed her with no response. I then found a phone number in an old hospital directory with her phone number. I called that number and found out that she no longer worked for that particular hospital. They gave me a phone number in the private health care sector that she is now working in. I called that phone number and left a message for her with my email address and phone number. She emailed me back about two weeks later and asked if she could do the interview over email. I mailed her a copy of the questions and a copy of the consent form with a return envelope included. She mailed her responses and the consent form back to me. After receiving her responses, I did a follow up phone interview that I recorded and transcribed via speakerphone with questions I had for her about her responses.

After interviewing the providers in the various departments at RC, I asked if they knew of anyone whom they thought would be willing to participate in my study and then 
I would contact them. This form of snowball sampling enabled me to find more participants. The ways in which I first made contact with the providers other than ones whom I had seen in person were primarily through emails.

Table 2. Nonresponse

\section{Nonresponse/Declines in Participants:}

Ridge Clinic

\begin{tabular}{|l|l|}
\hline 1 Decline & $\begin{array}{l}1 \text { Nonresponse after initial agreement of } \\
\text { participation. }\end{array}$ \\
\hline 3 Nonresponse & \\
\hline
\end{tabular}

\section{Patterns of Nonresponse}

There is no discernable pattern of nonresponse. Doing research with health care providers who are extremely busy can be problematic. I believe that the RN who originally agreed to be interviewed and then did not respond later because her busy schedule kept her from being able to participate. I think the three providers from RC who did not respond were due to similar circumstances. The P-AC who declined to be interviewed did so due to social shyness. Her email simply said, "I’m sorry, but I have to decline to be interviewed.” I asked the colleague who suggested I interview her why she might decline. He seemed to think that it was because of her social anxiety at being the center of attention, including being interviewed.

\section{Saturation of Participants:}

In grounded theory, sampling continues until the researcher feels that nothing new can be said about the concepts under examination and data has reached a thorough saturation point (Cutcliff 2000). In my two designated places of study, the saturation was high. 
RC:

There are five doctors who work solely for RC. I was able to interview four of them. The fifth doctor primarily works in another department and does not deal with these issues as frequently as the others. I interviewed three other physicians who occasionally work for RC that list women's health as a specialty. I interviewed one of the two P-ACs. Three providers were interviewed through snowball sampling.

IH:

I interviewed three of the four RNs who work with the Family Planning and STD clinics. The fourth nurse is the person I tried to contact a number of times with no response. I interviewed two out of the two nurse practitioners who contract with $\mathrm{IH}$.

\section{Data Collection}

I interviewed employees in face-to-face semi-structured interviews after receiving verbal and written permission from each individual participant. I used a standard approved IRB informed consent form. I also received permission from the administration of both places to conduct interviews of their employees. I used semi-structured interviews with the same fundamental list of questions for every participant. During certain interviews the participants and I engaged in a dialogue that did not follow the questions exactly. These dialogues were very fruitful and most participants had the desire to elaborate on the questions. Most of the questions were open-ended.

\section{Recording}

I recorded interviews on a tape recorder (with the permission of the participant). It is also important to note that some linguistic forms exclude women while at the same time making them deviant (Devault, 1990), so I tried to be as open as possible to different 
modes of language and the varying levels of education while conducting my interviews. The nature of my questions was often very sensitive, so I tried to be nonjudgmental.

I transcribed each interview from audiotapes, which enabled me to read and analyze the responses more accurately. The interviews took place in participants’ offices or employment locations so they might feel more at ease during the interviews. Only one interview took place in my office because it was more convenient for the provider. The length of the interviews varied from 25-50 minutes and were collected over a period of 3 months. As the interviews progressed, themes began to take shape as is consistent with the emergent nature of grounded theory research. The transcriptions took about 2-3 hours per interview. While recording data, I also simultaneously begin to develop theory. The concurrent interweaving of recording, data collection, and analysis is important to grounded theory research (Mellion and Tovin 2002).

\section{Question/Interviewing Considerations:}

My interviews were similar in structure; I used the same list of questions for every participant. However, I did not always ask the questions in exactly the same order and sometimes the wording had small variations. I found it necessary to rearrange the word order or question order for a variety of different reasons. First, if answers to questions I had not asked yet had already been answered by the participant, I choose not to repeat questions. Even though asking the same question in a variety of different ways can lead to interview thoroughness and consistency, I choose not to do this because all of the participants were on a very short time schedule. They are health care providers with demanding schedules. For most of my interview appointments, I had to schedule only twenty-minute time slots that went over the time limit. The providers gave me extra time 
to complete the interviews, but frequency I infringed on patients waiting for their appointments. I did not want to further inconvenience the participants by asking similar questions repeatedly.

The second reason that wording for some of the questions was changed depending on interview context was because of participant level of comfort. If I could sense that the participant was feeling uncomfortable with the formality of the interview situation, I would try to ask the same questions in ways that sounded less obtrusive to the provider. The third reason that questions were asked in different ways was if the participant had trouble understanding the question and needed clarification. Sometimes examples needed to be given in order for the participant to understand what I was asking.

\section{Instrumentation}

I did not create a measure of provider empathy or change of patient self-image scales devised before the interviews took place. This was because 1) this research topic is relatively new and no measures have been developed for comparison and 2) in grounded theory research themes and concepts emerge from the data during the collection and analysis process and not beforehand and 3) I did not interview patients themselves due to Health Information Portability and Accountability Act (HIPAA) regulations and IRB standards. However, a measure of provider empathy would be an excellent undertaking for a further study or for dissertation research.

\section{Study Completion:}

There are a few reasons why I decided to terminate my study and stop interviews. I could theoretically expand my study to include all of the providers who work in other departments within Ridge Clinic. My study is mainly about young low-income women 
with little or no health insurance that have STDs. The other providers who deal in reproductive health care do not see many cases of STDs (they are mainly involved in reproductive health care involving pregnancy and birth) and most of their patients have health insurance and are above the age of 30. Methodologically speaking, it would not make sense to expand this current study to include their views. However, in the future, it would make sense to study their views as well and develop a new plan of research comparing views of private providers whose patients who have a higher level of socioeconomic status and health insurance to views of public providers whose patients are young, uninsured, and low-income. 


\section{Findings}

\section{Chapter IV}

The summary of findings that follows below is deliberately organized. It follows a pattern that was influenced not only by the order and progression of interview questions, but is also grouped by provider responses. The narrative I developed from providers' experiences and attitudes merges into policies that could eventually have a positive impact on both providers' and patients' lives. The findings begin with the way providers see sexually transmitted diseases in a patient diagnostic context. The section discusses how specific STD diagnoses affect a patient due to differences in age at diagnosis and the type of STD diagnosed. The manner in which STDs are reported, or often unreported, is also discussed in this section "Providers' Views of Patients: STD Diagnostic Sessions." The second section, "Provider's Goals and Sensitivity,” demonstrates the occupational goals providers attach to their professions. It also shows how the level of experience a provider has or the number of years a provider has dedicated to low-income health care can demonstrate a commitment to patients and a high level of provider sensitivity and empathy. The last section, "Low-Income Populations and Policies Providers Advocate," illustrates the complex issues surrounding people in poverty with STDs. The final section of this chapter suggests policies advocated by providers that could improve sexual and reproductive health care for low-income populations and lead to better quality health care for at-risk populations.

The focus codes and patterns that emerged from the data are included in the appendix. A diagram, "Categories of Diagnostic Sessions and Issues Surrounding LowIncome Populations," which summarizes the findings section is shown below: 


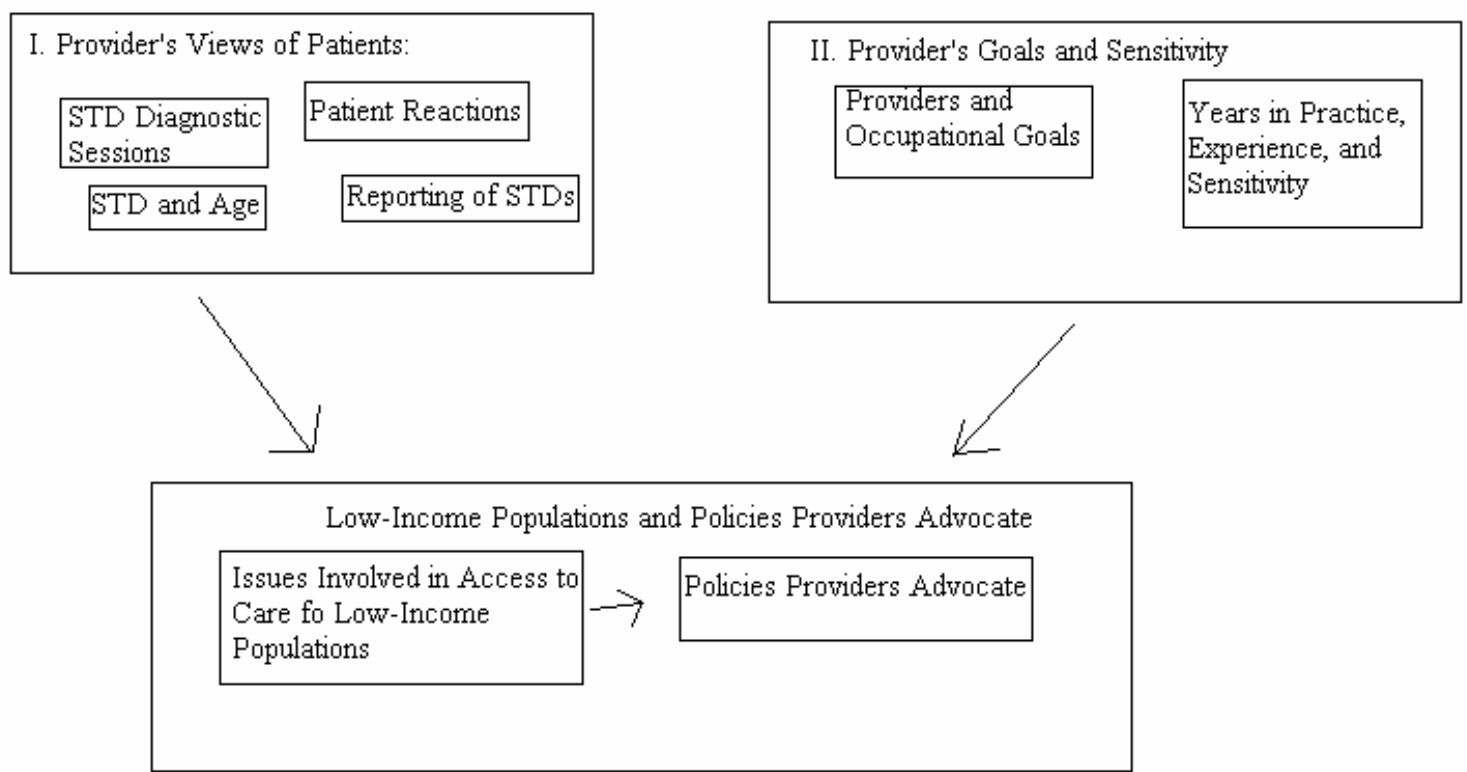

Figure 1. Categories in the Findings

\section{Providers' Views of Patients: STD Diagnostic Sessions}

Diagnosing an STD is an individualized and very personalized experience. Many factors that can make it an uncomfortable situation for a patient. An inherent power structure exists in seeing a health care provider because the patient turns to a provider for advice and help and is on some level submissive to the provider's wealth of education and information. In addition to the pre-existing provider to patient relationship, sex can be an uncomfortable topic of discussion. It seems that there should be a standard protocol each provider follows during a diagnostic session, but this is not the case. In order to navigate this complex process of diagnosing an STD, a provider must make certain decisions based on patient reactions, histories, and a list of health problems. The provider takes a history, then a sexual history, examines the patient, tests for STDs they might think are present based on what information the patient gives them, and counsels the 
patient. However, the way a patient reacts, and the way a provider reacts to the patient, depends on many factors.

The diagnosis of STD can be a traumatic experience for a patient. Several factors contribute to the degree of emotional distress or lack of distress a patient will experience during a diagnostic session. There are also different ways in which a provider responds to these emotional responses. The two main categories providers think contribute the most to a patient's level of emotional distress during a diagnostic session are 1) whether or not the patient simultaneously found out a partner was being unfaithful through their own STD diagnosis and 2) the type of STD diagnosed.

Oftentimes, when providers diagnose an STD, they are simultaneously diagnosing infidelity in a partnership. Negotiating the space between the patient and the empathy the provider feels towards someone who has just found out their partner has been cheating on them can be tricky for the provider. One RN negotiated this distance by informing the patient that a pap smear was not an accurate diagnostic tool and that the patient would have to come back for another test.

I can account for one that happened where a patient who was monogamous with a monogamous partner and a report came back with a report for trichomoniasis and that was very upsetting to her because it had social implications. So what I had to do was reassure her that a pap smear was not a sensitive screening tool for trichomoniasis. That you need to come in and see me so that we can do a wet prep and look. Cause that's the only way you can diagnose trichomoniasis is through a wet prep, not a pap smear. So that was really kind of unnerving and kind of distressing to some degree cause it was tense because there's infidelity issues running through this patient's mind of 'Why do I have trichomoniasis? I've been married for like ten years." You know. So it has a social implications.

At face value, this excerpt shows the provider being extra-cautious about making an STD diagnosis that could have further implications. However, by telling the patient that she would need to come back at a later time, the provider is also giving the patient 
sufficient time to let the idea of having an STD due to partner infidelity sink in. This time that a provider gives a patient in order to understand that they have an STD was a repeated tool providers used to help them educate patients. On the first diagnostic time around, providers often believed that a patient was too distraught to hear what they had to say. For example, one providers thought that patients “often don’t hear what you say after you say, 'You have an STD.' They miss the next 90\% of it.” Since providers believe that patients don’t always hear what the provider says after a diagnosis, many providers distribute literature to supplement what the patient might not hear. One physician describes his experience giving out information to patients.

Now, I think a lot of this [difficulty with diagnoses] is personally related to the media coverage and people's information bases they have when they come in or lack of information base when they come in. And trying to get through some of that barrier at least gives them some information because a lot of times, if I tell you that you've got herpes simplex virus and I start giving you a lot of information about herpes dadada. My gut feeling is, a lot of times that doesn't even sink in. All you hear is herpes and that's the last thing you hear. You don't hear any of the other information. So here, we've got some informational packets that we put together on HSV, on HPV, and we've gotten little handouts on HPNGU [Non-gonococcal urethritis (NGU) is an inflammation of the urethra often caused by Chlamydia], a lot of these things we give the patients to take with them because recognize that they don't hear all that you say at that time.

The "lack of information base" was a constant problem to which providers alluded. Literature was necessary to help patients understand their disease. Providers believed both young and older patients were not educated about their STDs. Consequently, they spent a lot of their first time diagnostic sessions teaching patients about what disease they have. Repeated phrases that patients asked where, “How could I have gotten this?” or “Where could I have gotten this?” Some patients just do not have factual information about how STDs are contracted or spread. Providers felt that patients with less knowledge 
about STDs had a more difficult time during the diagnostic session. Many patients who came in with herpes did not realize they could contract herpes through oral sex. Because of misinformation and lack of education like this, patients were often more angry with themselves or their partners than a patient who knew more facts about STDs.

In addition to a lack of basic information that can affect a diagnostic session, the type of STD diagnosed affects a patient's reaction. STDs other than HIV were put into two consistent categories by health care providers; bacterial (curable) and viral (incurable). When providers spoke about giving these STD diagnoses to patients, they referred mostly to the level of difficulty a patient felt about receiving a diagnosis and always rated viral STDs as being more emotionally difficult to diagnose from the provider's perspective across every practice location. A female RN who works for the local health department discusses the difficulty of diagnosing a viral versus a bacterial STD:

So, I think the hardest ones though really, are the ones that are not so much the chlamydia and gonorrhea that are bacterial, it's the ones that are viral because a lot of times with those with like HPV and herpes, you're telling them that, "You may have subsequent infections. Um, you know...This is something that can remain in your DNA.” Patients tend to get much more upset about those than something that they do about something that they know they can take a pill or drink something and then it's gone. So, that's a lot more education talking to them about long term. You know, involvement and how does that impact your sexual activity and your relationship with your partner and having children and all that. So that's much harder. I think to do. And you respond. And how you respond, depends a lot upon how they react to it as well. And some patients take it very well and other people are very upset and they're sobbing. "How did I get this? Does this mean that my partner was unfaithful?” No, it may not and so you've got to talk about that as well. So, those viral ones are the hardest ones clearly. And from an emotional standpoint, they're harder on both the clinician as well as the individual that's receiving the diagnosis.

Since viral STDs are incurable, the provider acknowledges that the diagnostic session

might be harder on both the patient and the provider. Viral STDs require more 
educational counseling from the provider to the patient about the long term effects of having a disease that will be with the patient for their whole life. Time during diagnostic sessions also varies according to the type of STD diagnosed. Normal appointments last about 20 minutes, but diagnoses and counseling of incurable STDs can take up to an hour for some appointments. Herpes and genital warts are STDs that providers repeatedly mentioned as being emotionally difficult for patients and time consuming for the provider to diagnose.

During my interviews, I never explicitly broached the subject of HIV/AIDS. The providers who mentioned HIV/AIDS did so out of their own accord and agreed that giving an HIV diagnosis was the most difficult out of all the STDs. I asked one woman, who is an RN in a local clinic that caters to low income populations, to rate her experience diagnosing HIV on a scale from one to five with one being the easiest and five being very emotionally difficult,

Five. That's a hard thing...I've only had to tell some one twice. I've only had to tell some one twice that they have HIV, which is really, it's just so hard. It's just heartbreaking. You've read about it and worry about it. So, the other ones, your other STDs like genital warts and herpes, that's difficult, but those are things that people can live with, I mean it's not, the HIV is definitely a five. It's extremely difficult.

It is extremely stressful for a health care provider to give an HIV diagnosis. Every provider who mentioned HIV put it in its own category, completely independent of the other STDs. A provider, who might able to keep themselves separate from the emotionality involved in diagnosing other STDs is less able to do so with HIV. Herpes and genital warts were also very emotionally difficult for provider's to diagnose. 
Another provider who is a nurse practitioner for both a local health department and a local free clinic discusses why viral STDs are more difficult diagnostic sessions than bacterial STDs:

It's always harder when you're talking to somebody about, "Yes, this is herpes. Yes, you will have to deal with this as a chronic illness for the rest of your life. You're 19 years old and the next 80 years is going to be spent managing your herpes." Um, is harder than saying "Oh, you have a bacterial infection, oh it’s GC or chlamydia, but we can treat this and you know, come back for a test in two weeks and I can promise you that it will be gone. It's more relieving.” HPV because it's so nebulous in its long term ramifications is very difficult for counseling.

This provider acknowledged that having a chronic illness changes the way a patient will have to think about their health for the rest of their lives. She pointed out that it is easier to give someone a bacterial diagnosis knowing a provider can tell the patient that it is totally curable. When the stigma attached to having an STD is added to the fact that the STD is incurable, difficult diagnostic situations can ensue. Oftentimes, providers believe that an incurable STD can change a patient's idea of their own sexuality.

\section{STD and Self-Image:}

I asked an MD if she thought an STD could change a patient's idea of his or her own sexuality.

I think a lot of times it can .Especially if it's a chronic type of thing. Particularly the viral ones. It can make people feel more vulnerable. I think, um, I think it makes them more fearful that they're going to have to disclose things about themselves that they feel stigmatized about.

This provider brings up the idea of stigma being connected to a provider/patient relationship and the vulnerable position that patients often feel they are in. This recognition by the provider that patients feel vulnerable in their presence when discussing STDs shows that providers are often aware of patients' feelings of stigma during 
diagnostic sessions. Most of the providers I interviewed were also sensitive to the idea of patients judging themselves when they found out about their STDs. One nurse practitioner who works for a specialized health care service that mostly serves people under age 25 was very concerned with how patients with STDs viewed themselves.

The main thing that I'd like to do is get the stigma of STDs removed. And that's what I always tell my patients is, we have to...Cause like I told you about that one young man, "Only scumbags get STDs." And you know, if there's one thing that I could change, that's what I would change would be people's views of that. Because like I say, what I tell my patients, no virus, no bacteria, is a judgment of character right? Can they tell who's a good person and who's a bad person? So I think the sooner we all get to that point, the better because it's all that moral stigma that makes people not come in, makes them afraid to talk to their partners. It's really the moral stigma that causes all of the emotional seqelae. It's really not medical. Like, herpes, I always tell my patients... Herpes is the most overrated disease on the planet, I think. Who ever cries over a cold sore? Nobody! This is the same thing. And yet, genital herpes, it's like the end of the world. At some point, I wish we could just all get over that.

This provider is very aware that the social stigma involved in groups of younger patients can be very damaging to their sense of self. She deals with STDs on a daily basis and knows that STDs should not have the societal weight they have since she believes they are just another illness. However, she also acknowledges that a patient cannot have this objective view when they are first diagnosed. Providers also think that this stigma causes patients to put a diseased label on themselves. One RN involved in reproductive health care said, "I know that as a general rule, patients feel that they are singled out or that they're identified and that they feel that it’s a scarlet letter, so to speak.” The societal STD stigma and scarlet lettering patients often bring into the diagnostic session can set up a framework for diagnostic sessions in which patients act out much of the emotional distress they are feeling within the exam room. 


\section{Patient Reactions:}

As the above providers have affirmed, a patient's reaction is often contingent upon the STD they are being diagnosed with and can manifest in many different ways. The patient reactions providers often discussed can be grouped into four categories. As one provider put it, “I think in general people are never happy to hear that they’ve been exposed or that their symptoms are consistent with an STD, I think that's pretty troubling to most people.” According to providers, the four categories of patient reactions that providers see happen most are 1) Anger and Sadness, 2) Refusal of Acceptance, 3) Changes in a Patient's Self-Image, and 4) No Reaction.

Anger and sadness are the two most common patient reactions that providers spoke about. Crying after the initial clinical diagnosis is a common occurrence in patients diagnosed with STDs, but specifically with incurable STDs. Patients will often make comments like, “Nobody will want to go out with me.” One registered nurse put it like this, “I’ve seen a lot of tears. Thinking, you know, 'How am I going to tell my partner now? What am I going to tell my partner? That I've got this virus? What's that going to mean for our sexual relationship and everything?' So a lot of tears, a lot of anger sometimes.” A patient is upset during the diagnosis because they are wondering about the changes in their sexual life they will have to make. The anger that patients often reveal after an STD diagnosis is usually directed at their partner because they assume that a partner has been unfaithful. Providers described many instances in which anger at a partner was the first thought that crossed a patient's mind.

Sure, you know, definitely where they're immediately assuming that a partner has been unfaithful. And they're angry and they're mad and, "Wait until I get home." And then you're trying to calm them down and say, “This doesn't mean that your partner has been unfaithful. It means that you probably need to sit down and talk about it and find out. But with some of these viral STDs we know that if either 
partner has come into a relationship having prior partners that they may have brought that STD into the relationship, so you can't be willing to point fingers. Okay?” So, I’ve seen a lot of anger. A lot of anger.

Providers are not only clinicians in diagnostic sessions such as this, but they become counselors, educators, and associates who must calm patients down. The provider wears many hats and sometimes the anger patients feel is directed towards them. This anger can manifest itself as a patient refusing to accept the diagnosis the provider gives them. The following excerpt is from a physician who made a diagnosis of herpes that a patient refused to accept.

I remember one young lady, when I told her that she has herpes and went over the information with her. And she came from a family that had a medical background. I can't remember if it was a dentist, a pharmacist, or something along that line. And when I told her what was going on with her, she just totally tuned me out and said, "You know, you're absolutely wrong." Actually, she came back at a later date and told me that I was very wrong. She had gone some place else a few days later and they told her that she didn't have herpes. So it's kind of...See, the thing is, for herpes, most of the time, you don't have to test for herpes every single time patients come in. It's a clinical diagnosis most of the time. In other words, you take a look at the history, you look at the physical exam and you make the diagnosis. Okay. And I made the diagnosis based on her history and her physical exam. She had a lot of ulcers on her vulva. You know, she didn't have anything. You know, she had some burning when she peed. She didn't really have any yeast type stuff. We tested for yeast, and we tested her for chlamydia and gonorrhea when she was in. And that stuff was all, turned out to be negative. So uh, if it looks like a duck, walks like a duck, and quacks like a duck, it's probably a duck. So I told her she had herpes and she came back later and told me that I was out in left field and that made me sort of angry to be quite honest with you. You know, I mean, I felt like kinda like she was an affront to me and she was questioning my intelligence, if you will, and maybe that's my own sensitivity to that thing. But I mean, I realize that, you know, maybe she was just acting out the anger I think that she was feeling by being told by somebody that she has herpes.

It is not uncommon, in many providers' experience, for a patient to react the way this patient acted. Diagnoses of STDs are often done clinically without further testing because some of the interviewed providers think that expensive tests are unnecessary. Frequently, 
this does not satisfy patients who want a definitive answer or feel the health care provider could be wrong. Refusal to accept the diagnosis, tears, or anger directed at themselves, their partners, or their providers are frequent reactions, but for the most part, providers think that the majority of patients want to know immediately and definitively if they have an STD. The physician in the above quote was not comfortable with a patient who questioned his medical authority. It would be interesting to further study other patients who met the same reaction from providers because patients who cannot afford further expensive testing must take a provider's clinical word for the disease they have. Providers can be wrong because they are human.

Although an uncommon occurrence, providers were most worried about patients who exhibited no reaction at all to an STD diagnosis. Some providers feel that these patients might already have a very bad self-image. Patients with no emotional reaction worried one registered nurse because she felt that there might have "already been something that has gone on with their relationships with either partners or families before that it [a diagnosis] doesn't seem to bother them. Or is their self-image that bad already that this doesn't seem to faze them?” Because of the stigma attached to most STDs, finger pointing by the patient directed at either the provider, their partners, or in many cases at themselves, can result. This inward judgment a patient makes about themselves can manifest as a change in their self-identity.

When providers were asked about key phrases patients used when diagnosed with an STD, “I'm never going to have sex again,” or "Nobody will want to go out with me," were common responses. Providers felt that patients experienced themselves as less desirable sexual beings secondary to an STD diagnosis. Immediately following a 
diagnosis, patients began to change how they thought of themselves. A diagnosis of an STD is significantly different and more difficult for a patient than other disease diagnoses, even though most STDs are not life-threatening if caught in time. The stigma attached to STDs oftentimes causes patients to think of themselves in a negative light. A nurse practitioner describes one young man who judged himself quite severely after an STD diagnosis.

In particular, I remember one young man...it always bothers me more when men cry. That's really bad. And one young man who said, only, I forget what word he used. "Only people who are scumbags get STDs." You know, and you can see that he's really judging himself and I said, "Well I don't think that and if you think that, you're going to have to change what you're thinking there.” And at that point he said, "Well, I can't." And so, that's somebody I really worry about.

This provider was especially sensitive to patients and spoke repeatedly about being worried about her patients, but was more worried about this patient because he perceived himself as subhuman. Providers are not trained counselors, but must take on a conciliatory role in cases like this. Most providers feel that, in time, patients will come to view themselves more positively after learning more about their disease or having time to reflect on actually having the disease, unlike the male patient described above. Other words and phrases that indicate a change in self-image used by patients are "Ashamed, dirty, slut...and almost always you hear, 'I feel so ashamed, I feel so gross.'” Other times, patients feel that an STD diagnosis only happens to other people and cannot believe it is actually happening to them. These feelings of inadequacy or of feeling dirty can cause patients to think they are no longer available in the dating arena because no one will have sex with them again. In extreme cases, this can cause years of abstinence. One 
male physician worked in both private practice and in public clinics spoke about abstinence in patients after being diagnosed with an STD.

I think it's just devastating for a patient. I mean, I've seen patients, who have become abstinent for years, secondary to this, who have significant sexual dysfunction. Secondary to a diagnosis of a sexually transmitted disease. I've seen relationships destroyed, marriages broken up. Um, the morbidity is extremely high. The psychological morbidity is extremely high.

This provider recognizes that outside of the clinical session serious consequences can occur in a patient's life after being diagnosed.

\section{STD and Patient Age:}

Many providers believe that age contributes to a patient's reaction to an STD diagnosis. There is no consistent pattern as to which age group providers think have the most difficult time with an STD diagnosis. Across both interview locations and across the ranges of populations providers see, providers thought that difficulty handling diagnoses is not so much age dependent as it is dependent on individual experience. A history of depression, mental, sexual, or physical abuse and education level can affect a patient's reaction. One nurse midwife who works with mainly young low-income women felt that a lot of her patients were abused and felt like sluts because they had been told their whole lives that they were sluts and whores. In her experience, the younger population had a more difficult time. Alternatively, another provider who works in the same clinic and is a physician felt that the older, middle class population has a more difficult time with an STD diagnosis because their lives are more disrupted. He felt that the young lower income population was more used to the hard knocks of life.

The reasons providers gave for the younger population having a more difficult time revolved around less life experience. Since younger patients have less life 
experience and less emotional maturity, they are more likely to experience greater emotional impact. For many young people, it is the first real negative thing that has happened in their lives. The diagnosis often causes young people to realize that they are mortal. On the other hand, some providers believed that youth helped a patient to be less affected because they are more educated about sex than their older counterparts. The younger population has grown up with the Internet and more access to information. They have also grown up with sex having less of a stigma with more open discussion. Some providers believe older populations might have a more difficult time dealing with a diagnosis because they grew up in an era where sex was not talked about as openly or as often. In addition, many of the patients who come in with STDs in their forties, fifties, and sixties, are newly single either from divorce or death. They are new to a market that has more incidences of incurable STDs and are not always educated about the risks. On the other hand, patients in their thirties often have a more difficult time dealing with a diagnosis particularly because they do know the long term health risks. For example, knowing HPV is linked to cervical cancer can produce more worry and distress.

\section{Reporting of STDs:}

Providers believe that the statistics surrounding STDs are probably quite far from being accurate. They are most likely gross understatements. The only STDs that have required reporting include gonorrhea, syphilis, chlamydia, hepatitis A and B (American Social Health Organization 2005). This leaves out viral STDs such as HPV and HSV. Even required STDs are frequently not reported. Providers state that common underreporting is due to factors such as fear on the part of the patient, state regulations 
that do not require reporting, or a provider not knowing how to report an STD. One

physician described his lack of understanding with the reporting system.

Sure. And I don't think that's abnormal [for STDs not to be reported]. Now, if you send a culture out for chlamydia or GC, I think there's an automatic trigger that sends it to the health department. Quite honestly I've been doing this for 17 years and I have no idea what I'm required to do as far as reporting STDs. If I see somebody with...I...When somebody comes in here confidentially and wants confidential treatment and they have herpes virus or human papillomavirus...I don't think any of that's reported.

The "trigger" that this provider spoke of was mentioned numerous times by other providers. However, unless the "trigger" is another employee in the health system, the STD does not get reported. Many providers assume another provider is actually making the report to the county health department. Also, many providers do not know how to report STDs and honor a patient's request for confidentiality. One reason why a patient might not want their STD reported could be because they are afraid that it might affect their insurance or because health departments often call sexual contacts to check on the spread of the disease.

According to some providers, most of the viral STDs are not required to be reported. The STDs that are reported on a regular basis are gonorrhea and chlamydia, but HPV and HSV are not. One reason that herpes is not reported on a regular basis is because providers make the diagnoses clinically. Since it does have to be proven by culture because the provider can visually see the herpetic lesions, it often does not get reported. The reporting is often done by lab assistants or professionals involved in the culture or test. When there is no test, there is often no report. Another reason that STDs are frequently not reported is because the process can be complicated to maneuver. One female physician put it like this, “At a typical doctor’s office it's a matter of, you have to 
go look up the phone number, pick up the phone, call somebody. It’s not very easy.” When a provider is on a tight time schedule seeing a new patient every fifteen minutes, the extra time it takes to report an STD is not always worth it to the provider. Skipping the report due to a tight time schedule is especially true in clinics where low-income populations are treated. There tends to be long waiting lists to even get care and providers feel it is more important to treat patients. In addition, many providers are not convinced of the value of reporting, unless it is a public health issue.

Another that STDs might be grossly underreported is because of partner reporting. Many low-income patients cannot afford many trips to the doctor, but it is necessary if one of the partners is diagnosed with an STD. The chances are very high that the other partner will also have the STD and need treatment. In many clinics, providers will treat the partners without physically seeing them or write prescriptions without going through lengthy cultures and tests. This practice is very helpful for low-income patients where only one partner might have health insurance or the partner might not be able to get away from a low-income job with inconvenient hours. However, the provider is not protected by law if the other partner develops a complication to the STD treatment such as an allergic reaction. Also, the partner's STD is usually not reported in these cases.

\section{Providers: Occupational Goals and Sensitivity Providers and Occupational Goals:}

A registered nurse who works for IH describes what she values from her job in the quote below. 
I think I view my job as something that the majority of the time, probably $90 \%$ of the time when I leave work and I go home I feel like I've done something worthwhile and that in itself is enough that even though sometimes when you work for a state or county agency your pay is not going to be as good as a lot of the other places where I could go and probably make $\$ 10$ more an hour than what I'm making here. I don't know that I would have that sense of satisfaction. And sometimes we don't have that sense of satisfaction. We fail sometimes. You know. And we see that with both the family planning and STD and by that I mean some one that you work with closely and try to keep them from you know uh, becoming pregnant when you know that they may not have wanted to or the family has not wanted them to and you fail. But at the same time, you still feel like you've at least been able to impact some one's life in most of the time a positive way. So, from that standpoint I feel very good about what I do on a daily basis...Because I feel comfortable working with both males/females of lower socio-income. I feel like I have a tolerance for different lifestyles and all those things make me feel comfortable in working with the population that I do.

This nurse works with low-income patients regularly. It is clear that she does what she does for the patients. This orientation is true for many providers who work with lowincome populations. Her connection to her patients is obvious, even though she feels that she fails sometimes when a patient contracts an STD or has an unwanted pregnancy. Another provider describes his emotions when he feels he has failed in his job.

So much of what we see is preventable. I feel that we could be doing a better job equipping people with knowledge. So many people make the same mistakes over and over. I see their tears and feel some anger, myself, that it was preventable.

Providers see themselves as educators and many times, can see themselves as failed educators. It can be exhausting to know that with a little education, many diseases could be prevented. Every single provider interviewed mentioned education in one form or another. Providers educate both patients and other medical students and feel that it is a very important aspect of being a healer. Educating medical students is a way to stay in touch with their healing craft and a way to "maintain some humanity in medicine." 
Providers feel that they should educate patients about how to better take care of themselves and their bodies.

\section{Years in Practice, Experience, and Sensitivity:}

The longer a provider practices and the more experience they acquire, their ability to emotionally extricate themselves from the actual disease if it is not life-threatening increases. They tend to see this separation as "professionalism," while a patient could construe it as an insensitive distance. This professional space is necessary for the provider because they see these diseases on an everyday basis. If they became too caught up in their patient experiences, they would cease to be efficient and good caregivers. A female nurse practitioner describes how she sees this distance.

I think part of being mature as a professional is, because I tend to be a very empathetic person, and one of our doctors here told me, "Tracey, it's the patient that has the disease.” And I think that's really important and you're not a good helper if you're going to get burnt out. So part of it is learning to still feel empathy, but on the other hand, not to get yourself totally wound up in it, either. So I mean, you'll find that too. It's just learning where that distance is, where you can still have, like I say, good empathy, but it's not me. So you have to keep your professional distance.

Her level of empathy and sensitivity is evident in the way she describes wanting to help the patients, but she also recognizes that her job is not to get too caught up in their emotions. The level of professional distance can help the provider keep their sanity. Experience is another aspect of caring for patients that can make the job easier for providers. It is inevitable that once a person does the same thing many times, the job will become easier and less intimidating. The experience that helps a provider emotionally detach themselves from the patient does not always mean that provider sensitivity 
towards the patient is diminished. It means that their sensitivity towards the disease is.

One male physician describes how experience can aid in the diagnostic process:

Well, in some respects I think it's easier because I've got a lot more experience. When you first start out you don't have a lot of experience so you deal with a lot of issues that you don't have answers for or at least you've never thought about what are the answers for these questions. And you don't know until people start asking you questions what the situation is. So I mean, I've got a lot more experience now, so in that respect it's easier.

This provider can better anticipate questions from patients because he has been through the diagnostic process many times and received many questions. Later in the interview, this provider claims that experience does not affect the treatment of the patient, but that the patient can often mistake the professional distance for insensitivity. In the realm of sexually transmitted disease, this professional distance can become misconstrued in the patient's mind since STDs carry certain societal connotations. First time diagnoses are often a traumatic experience for a patient, especially if it is a diagnosis of HPV or HSV, both of which are incurable. Health care providers witness many episodes of the effects of this trauma on a daily basis.

Because of the frequency of diagnoses, a provider can become desensitized to the stigma surrounding STDs because they deal with them on a daily basis. One female physician said,

Pretty much any time anyone has an abnormal pap and they have HPV, people get very distressed. And almost at times it seems puzzling because to us health care providers who are dealing with it everyday, we lose touch with the fact of how stigmatized it all is. But, yeah, that's a very common occurrence. Several times a week there's an upset young woman who's coming for a colposcopy or further testing after an abnormal pap is very distressed by this positive viral test that more than $1 / 3$ of the population has. 
It is evident that providers can loose touch with how traumatizing it can be to have an STD since they see cases daily. A male physician called himself "desensitized" because he diagnoses around 3-6 cases of STDs per day. Physicians who had been working in health care the longest (the range was six to 33 years in women's health care, with a mean of around 19 years), were the most likely to describe their diagnostic sessions as perfunctory. Nurse practitioners and registered nurses were more likely to use phrases with more sensitive connotations such as, "I really worry about the patient who..." or "Having an STD does not make them a less valuable person" or "An STD is not a judgment of how clean or reliable and how honest you are, but just one of the realities of life.” The small language difference noted above is most likely due to years in practice and not type of provider. The participants spoke very homogenously about their experiences because most of them have been involved in health care for low-income populations during the majority of their professional career. It takes a certain type of person to consistently work longer hours and for less pay. All the participants spoke with sensitivity about patients with STDs.

Talking about STDs is much easier for providers because of the professional distance, because they are educated, and also because they have been through the process so many times. However, the discomfort level discussing STDs can still be a factor in the provider-patient relationship. Providers feel that patients can sometimes be uncomfortable discussing their problems with them. One physician describes the patient to provider language barrier,

I think the biggest barriers are patients' unwillingness sometimes to talk about such things. I think providers, students and residents, all of us have a certain discomfort level of how are we going to approach a patient who might not be 
comfortable talking about sexual issues and how are we going to do it in a way that's not uncomfortable for everyone involved.

This provider discusses the difficult language balance that exists during diagnostic sessions and acknowledges that she might not know how to approach every single patient. The provider has to be very careful to explain health issues in ways patients can understand, while also being empathetic and understanding because there is a stigma surrounding STDs.

Health care providers who consistently deal with patients with a double stigma (low socioeconomic status and an STD) regard themselves as having a high level of emotional empathy. Providers who work with low-income patients on a daily basis noted they have a certain comfort level for dealing with special populations.

\section{Low-Income Populations and Policies Providers’ Advocate}

\section{Issues Involved in Access to Care for Low-Income Populations:}

Providers who treat low-income populations and who deal with sexual and reproductive health care in general work with special circumstances on a more intense level than other general practitioners such as child care, transportation, time off work, domestic violence, and rape. Domestic violence and rape are present in every social stratum. However, since most low-income women seek healthcare from public clinics, abused low-income patients are more likely to be visible to their communities. Transportation and child care are difficult for low-income populations to afford and lowpaying jobs often do not have paid time off. Other issues involved in low-income populations' access to health care can also make treating low-income women with sexually transmitted diseases difficult. 
Providers think that the greatest obstacle low-income women face when gaining access to care are problems with health insurance, Medicare, and Medicaid. The presence or lack of health insurance dictates what kind of care someone will get. The provider cannot just give away free health care whenever they want because there are structural systems in place that prevent this. If a patient cannot pay, they will most likely choose not to have a test done or the provider must give less desirable options. For example, a colposcopy, which is a test that looks for cervical cancer and/or HPV after an abnormal pap smear, typically costs between $\$ 400$ and $\$ 500$ dollars in the state of West Virginia without health insurance. Many times, a patient has to choose between some essential item such as food or the colposcopy. The patient cannot get the care he or she needs or deserves. From an outside perspective, this may seem like provider insensitivity. However, this is not the provider's fault. I asked one physician if she felt that insured patients sometimes receive better care.

I don't think physicians intend for that to happen but uh, if you hurt your knee and your insurance said I could get an MRI for that...Sure, that would tell me whether you should see orthopaedics. Or you didn't have the insurance to get the MRI that costs a couple of thousand dollars, you end up being treated differently. It's not that I as a physician chose to do that, but life circumstances tells me I need to treat you a different way because you can't or you won't get the MRI, for instance. So we try to go about it a different way. Can we get it paid for, can you pay a little bit at a time, can we see if it will heal on its own which will tell us that the MRI probably wasn't needed in the first place. Can we get you into orthopaedics to see them first? And I know a lot of places, if you don't have insurance you can wait six months and I'll take the paying patient first. So I don't know if in primary care we treat people differently. I think there may be some differences depending on insurance how quickly you get in and that sort of thing.

The "different ways" this provider went about trying to help the hypothetical patient were not first choices for either the patient or the provider. The provider is forced to make health care decisions based on a patient's ability to pay. The provider cannot take on the 
monetary burden for an MRI that costs thousands of dollars. Nor can the provider ask the institution for which they work to take on the financial burden. So the provider is forced into a bind to choose between the lesser of two evils. This predicament shows the need for better health insurance coverage, not necessarily just more free care for low-income people.

In other instances, uninsured patients will choose not to have certain tests done. They might flat out refuse necessary blood tests or ultrasounds because they cannot pay for it. Even when a patient has access to free tests, such as pap smears, the tests are often not as good as pap smears for higher income women. Many pap tests given at "free" clinics do not test for HPV because pap tests that test for HPV are much more expensive. State clinics that offer free and reduced-cost health care often do not have the funding to provide the most up-to-date tests.

Every provider interviewed works for a public institution/entity with public clinics and most had criticisms of how low-income patients might be treated in the private sphere. One nurse practitioner thought that private physicians treated uninsured patients differently than the insured patient. Uninsured patients do not always receive care that is as thorough care as someone with private health insurance. She said, "It's kind of patch them up and send them back to the free clinic.” Another provider thought that one reason insured patients might receive better care is because providers know that they will be getting more money from them.

The kind of health insurance a patient possesses can also influence how a patient is treated. According to many providers, the Medicaid system is flawed. Reimbursement issues prevent providers from being able to provide good care. A pap smear is reimbursed 
at about $\$ 14$, according to one physician, but is extremely labor intensive and should be reimbursed much more. The reimbursement for a Prostate Specific Antigen (PSA) for men is about $\$ 40$, but is much less labor intensive than a pap smear and is unproven in its efficacy. This gender-bias from Medicaid towards men's health care is also shown in the contraceptive inequality so apparent in many private forms of health insurance. Another provider mentioned that many private forms of health insurance cover Viagra for men, but not birth control pills for women. This inequality distresses many providers.

Medicaid also reimburses much less for health care than private health insurance and thus providers are forced to see many more patients to offset the cost. Therefore, a provider who sees more patients with Medicaid will be busier and spend less time with their patients. Providers who see more patients with private health insurance will have more time to possibly discover diseases and problems because they do not need to rush through seeing as many patients as possible to make enough money to cover their overhead. I asked a nurse midwife if she could think of anything to help the situation.

I don't know what the solution is. I mean part of me thinks socialized medicine. The Medicaid system isn't working. I do think there should be a bigger push for health departments, you know, based on income. If somebody is working and they can't afford health insurance, some kind of care system for people; for women who, especially the women in between and the thing with Medicaid...You better get everything done while you're pregnant because in just seven weeks after you're done, it's done regardless of what diagnosis. And these people get lost in the cracks. I mean, I don't know what the answer is. I find it very frustrating. Especially at the health department, we had the only place these women could go. Because most of the patients we saw, they didn't qualify for Medicaid, but they couldn’t afford health insurance or their employer didn't offer it. We had one free clinic. And the waiting time to get there, if you could even get there, was forever. So hopefully it wasn't something serious. I remember seeing a lady at the health department. I thought she had cervical cancer. I had never seen the kind of polyps she had on her cervix. She hadn't had her pap smear for nine years. The physician that employed me, I said, “She doesn't have any money, she doesn't have any insurance, please, look at her." And he did the colposcopy and he took it off for free. You don't find that very often. And not because health care providers don't 
want to help people, but your employer sends you every month your RVU report. And if you haven't dotted your i's and crossed your t's, they charge you back where you're not making enough money, according to your contract. They drop your salary or they terminate you. And so it's very hard to balance quantity and quality.

This provider mentioned another problem with Medicaid. Women who earn too much money to be on Medicaid but cannot afford private health insurance are covered by Medicaid during pregnancy, but not for long. Hardship can occur if a woman has a disease after the birth of her baby and has the double expenditure of caring for the baby while she has the disease, but without money for either. This provider also mentions that providers often cannot give free care without getting charged for it or fired. They are in a double bind because they want to help the less financially fortunate patients, but will not help anyone if they are fired and cannot care for any patients.

Confidentiality is another problem with health insurance that providers were concerned with. Young patients who are still on their parent's health insurance can get penalized because their parents see what medications they buy. Providers feel that this often frightens young patients away from filling prescriptions and buying certain medications because they do not want their parents to find out that they are sexually active or have contracted an STD. This issue can also prevent young patients from receiving further treatment from private physicians because their parents will see what they are being treated for when they pay the bill.

Lack of insurance can also mean that low-income women will have more frequent STD outbreaks because they cannot afford to pay for medicines, such as suppressive therapies. Valtrexx, a medication used in the suppression of herpes, costs around $\$ 9$ a pill without insurance. So an uninsured patient who cannot afford to pay $\$ 9$ a pill for 
suppressive therapy has to, in one provider's words, “just tough it out.” Providers will try to give out the free samples that pharmaceutical representatives bring, but pharmaceutical representatives typically do not frequently give out samples to places where uninsured patients are treated.

Lack of availability to afford medications can also translate to unwanted pregnancies. One nurse practitioner discusses funding problems and giving out birth control at family planning clinics.

So people who expect to get supplies, sometimes I can only hand out three and four month supplies, even in an adolescent clinic...Well, a 17 year old isn't going to show up every three or four months to get packs of pills, you know, she then...There's this, I was late a month, I couldn't get there, I didn't have a ride, so I missed a pack of pills and in the mean time they've gotten pregnant when had the financial resources or drug availability have been there, typically birth control pills and if I had handed them a year's worth, I could have avoided a pregnancy. So that issue... One clinic I worked at, I could only had out 3 months' supply at a time because that was all we budgeted for.

This provider also mentions transportation to and from the clinic, which can be a major problem for a young person who might not have access to a vehicle or to a person who cannot afford a vehicle. Transportation issues are especially big problems in rural areas where patients must drive long distances to receive care. Providers consistently list transportation as a problem patients have when accessing the free care at public clinics.

It is also difficult to find someone to take care of children when a woman visits a publicly-funded clinic. Women are more likely to be caregivers to children and are also more likely to be the partner in charge of birth control. Accessible birth control options for low-income people typically rule out men, with the exception of condoms. The woman is in charge of getting and taking the birth control pills, so a larger burden lays on her. She must find a ride to the clinic and usually either bring her children with her to the 
appointment or find someone to take care of them. Getting to the clinic can also prove difficult because low-paying jobs are not likely to let a woman get paid time off from work. Times that clinics are open are also obstacles low-income women face.

Clinics can take all day.... Low-income women have to go into clinics and they have to take a whole day out of their life because they have to come in, they have to skip class, they have to do this, they have to do that, and then, they all get seen by medical students. I don't think it's fair. It just isn't very sensitive to people's needs. It shouldn't be 8-4, rigid hours. WV, we have such a high cervical cancer rate, but a low rate of women who get pap smears. Because places where you can get free pap smears are not open at times when women who work for McDonald's can get to. And that sort of thing. Clinics should be seven days a week. It should be in Kroger's.

This provider's frustration with the current system is evident in her description of barriers to care for low-income women. Even when a woman can get off work to come to the clinic, find a ride, and find someone to take care of their children, the clinics typically have long waiting lists to get in or only offer a few clinics a month.

The viral STDs such as herpes and HPV often require many treatments. So the process low-income women must go through to get care is repeated over and over in a short time frame. Repeatedly having to go to a clinic can cause stress and financial hardship in addition to the emotional impact of the diagnosis of an STD. One nurse midwife discussed a young low-income woman who was diagnosed with genital warts.

Well I had a patient, young girl, 16. Just a terrible life history, abuse. And took care of all her siblings. And she came in because she had something "down there" and was scheduled to see one of the male physicians. When he walked into the room she was pretty hysterical. And so he came out and asked me to see her and when I went in to talk to her she said, "I have something...” It was very hard to get her to talk about..."I have something down there. And all I've done is sit in the bathtub. And cry for three days." It just told me how difficult it was for her to come in and how ashamed and she knew it was something, she just didn't know what. It was truly the worst case of HPV I've ever seen. At 16 years old and that's very easy to diagnose. She had just multiple. She was. She was just absolutely devastated and hysterical that she had given it to her little sister that she had taken 
a bath with. And it was very traumatic for her. And I ended up having to treat her with multiple office visits with acid to take them off. So that was a lot of teaching and...transportation issues. Especially in WV, these girls can't get here. And Medicaid, some insurances don't pay for topical treatment they can do at home so they are forced to whether they want to make it a private issue or not, they're forced to be and it's terrible because some women are just so ashamed that they don't come when they should.

Many important issues arise in this excerpt. The patient in this story has a history of abuse and takes care of her siblings. Her history of abuse was so severe that she was frightened of being treated by a male physician. She had a difficult time coming in to be treated because of the emotional feelings of shame she felt in having an STD. Also, her low-level of education did not allow her to understand the transmission of HPV. Because of problems accessing care, low-income patients will frequently miss appointments. The same provider explained why she thought missing appointments could make low-income people look bad to their providers and why low education levels can make it difficult.

They have a lot harder time. They miss a lot of appointments. They're labeled as 'No show.' 'No show.' And you know people, some providers are put off by people who are repeatedly no show without finding out why. They don't have access to the Internet. They can't look up the information. If you dropped out of high school in eighth or ninth grade you don't have the knowledge base to really put it in the right context, so I think they have a lot harder time.

Providers who treat low-income women on a daily basis must have special talents and high levels of empathy because of all the issues surrounding difficulty in accessing care. They must be willing to put up with patients missing appointments and understand that it is not always the patient's fault. They must be willing to make less money and have fewer supplies and resources. They must deal with patients who might be more emotional during diagnostic sessions because they have fewer emotional support systems at home. They must see patients who rarely have had provider consistency or medical 
counseling. Less medical counseling means that patients will have more medical problems such as obesity in the long term. In addition, the provider might have to take more time finding out what is wrong with the patient because the patient might not have the educational background to know what they have. Low-income populations also have a stigma surrounding them.

So many people will say to me, “I don’t understand...I don’t understand how you can do that on a daily basis. How can you, how can you work with these people day after day when they don't make any attempt to get a job. They'll go out and they'll buy video games or something like that.”

The stigma surrounding low-income populations is evident in the way this provider describes being approached by friends when asked about her job. But providers who deal with low-income populations are more willing to endure this stigma and all the other issues surrounding low-income populations accessing care or else they could simply get a job elsewhere. Many years of working in lower-paid provider jobs such as some of the jobs involved with lower-income populations could signify that a provider might not be able to get a job elsewhere. In this case, the level of care could be diminished. The long time frame that all of the participants interviewed have spent working with low-income populations (the mean was 19 years) more likely suggests these providers are willing to stick out the negative aspects of care with low-income populations and receive satisfaction from their occupations and helping people.

\section{Policies Providers Advocate:}

1. Funding

"Funding, funding, funding!" These are the words from one nurse practitioner who advocated emphatically for more money in her clinic. Almost every provider 
mentioned the need for more money to be allocated to "free" and reduced-cost sexual and reproductive health care in order to better serve low-income populations.

\section{More Sexual Education and Funding:}

As I previously stated, every provider interviewed mentioned education in one form or another or alluded to a patient's “lack of information” base. Many providers would like to see more sex education beginning around seventh grade. Providers think that abstinence-only education does have merits, but abstinence needs to be presented as the ideal, not the only option. Abstinence education should be included as part of a more rounded discussion about sex. Providers feel that young people should understand how disease are contracted and spread. One nurse practitioner spoke about abstinence-only education.

I really hate to see abstinence being the only um, policy supported and taught in high school. I think you can present abstinence, "Well, this is ideal.” And I think for even that group of patients you can say, "Those people who wait until they're 19 end up with less lifetime partners, have less problems in life." And thus encourage people to wait, but you know, people don't wait. Think about before we even had birth control, people didn't wait till they were married. You can't stop adolescents from having sex. So barring that you may delay a few couples, but not most, um, making it safe and making birth control available so you don't have lifelong ramifications for irresponsible behavior that's typical of an age group under age 25. And I was as irresponsible as anyone else in that age group. You know, some are luckier than others.

She understands that sometimes people make irresponsible choices during their younger years, but she does not feel that they should have to suffer for the rest of their life for one bad choice. Providers feel it is important to give the younger population tools and education to equip and protect themselves. Also, sex is an ever-changing phenomenon. One provider mentioned that the discussion around sex should be expanded to include 
discussions of how to stay safe during oral and anal sex. Sexual preferences and practices are changing and sexual education curricula should change to keep up.

\section{Providers' Treatment of Partner Protection Laws:}

When two people are involved in a sexual relationship and one has an STD, it is probable that the other partner will also have the STD. Providers spoke of instances where a woman would come in for treatment of the same STD many times because her partner refused to come in for treatment or was unable to come in for treatment. In this manner the patient would contract the same STD from their partner over and over. Providers often will go ahead and write prescriptions for the partners without physically seeing them. This practice is illegal, but necessary for many low-income populations that cannot come to the doctor many times. One registered nurse felt as though she was not doing justice to her patients by treating only one half of the equation, or one partner. She and many other providers believed they should not be liable if something happens to the

partner. A law protecting providers if they choose to treat the partner without seeing them would be very helpful to the provider, but also to low-income patients.

4. STD Screenings for All Annual Appointments and Counseling Appointments:

In many cases, female patients are seen only once a year for their annual pap smear. One physician spoke about how more counseling specifically at the time of the annual appointment could really help to educate populations. A more concerted effort during the annual exam aimed specifically at education about STDs and unwanted pregnancies could help to get the word out about STDs. Patients do not always receive information about STDs after they’ve just been diagnosed because of emotional distress, so the annual appointment is a good time for intervention. He believes that that time slot 
is ideal because the patient is coming in without a complaint and would be more apt to

listen because they would not be worried about having a problem.

The annual appointment is also a good time to screen for STDs. One physician

felt that every single patient should be screened for all STDs at every annual appointment

because you are never certain about who could possibly have an STD.

I just lectured to the med students today and I was showing them a case of gonorrhea. It was a theoretical case, but it was based on a real patient I had when I was in medical school. And she was a 14 year old girl and she presented with abdominal pain and because her uncle was a physician on the faculty. And he was swearing, they were all swearing that she had never had any sexual activity. It turned out that she sat around the emergency room for almost 12 hours. She had what's called a tubo-ovarian abscess. And she ended up having to have a total hysterectomy and almost dying at age 14 because again here I'm saying, everyone should just be targeted. That way you're not drawing any inferences about people's behavior. If you do it for everyone, you're going to pick up cases like this. She was missed and she had a 12 hour delay in treatment which may have resulted in basically, she's infertile now. I say, you need to screen everyone because particularly if a teenager comes in with her parents, she's going to be denying everything. Okay and you really can't pay attention to the denial because understanding that there's a lot of social pressure and a lot of familial pressure to deny but that still means that she may have a disease. And these are very real diseases with bad outcomes. Like that young woman had. So you try to get them alone so you can talk to them, but the easiest is, you just screen. You just assume that everyone is just doing it and everybody's at risk and that way you don't have to make a value judgment about whether or not somebody's telling the truth or whether or not they're prone to do it. You just take care of it.

Screening every patient at every annual appointment could prevent cases, like the young girl above, from happening and could possibly save lives. However, not all providers I spoke to felt that everyone should be screened at every appointment. No provider said, "Do not screen for STDs," but some providers take a sexual history and determine if a patient should be screened. Sometimes, if the patient tells the provider that they have been in a monogamous relationship for a very long time and were screened at the beginning of the relationship, the provider won't screen for STDs. However, practices 
like this can leave out many people who might have an STD due to partner infidelity or who might have had a viral STD for many years and not known about it. Screening for STDs at every annual appointment allows the provider to say, "This is just routine," and helps the patient not to feel like they've been singled out.

Another policy that providers think could help them is more time for counseling of patients after an STD diagnosis or separate appointments simply for counseling. After a diagnosis has been made, providers need a lot of time to discuss the ramifications of the disease, treatment options, and sexuality after an STD diagnosis. Patients will usually have a lot of questions that they might think about until after their appointment. Standard separate appointments specifically to discuss the STD could help providers and help patient understand their disease more thoroughly.

Policies suggested above could help our low-income populations to access sexual and reproductive health care on a more frequent basis. These policies also have implications for the prevention of STDs. The suggested policies also offer a deterrence towards perpetuating the stigma attached to having an STD by providing education and counseling to patients. By providing more funding for STD education programs and by helping providers who treat low-income populations on a daily basis, many patients' lives who are living with incurable STDs could be improved. 


\section{Conclusions and Implications}

\section{Chapter V}

Little research has been done studying provider’s attitudes towards low-income populations with sexually transmitted diseases. The scant research that has been done on sexual and reproductive health care providers [Ascribe (2003); Danielson et. al.(1999);

Family Practice Management (1999); Nack (2002); Neff et. al. (1998); Mogilevkina et. al. (2001); O’Connell (1997)] does not go in-depth about providers’ specific views regarding patients and does not adequately assess what a provider wants to see in future policy. When asked what policies they would like to see that could help them do their job better, many providers looked surprised and grateful that a researcher cared about their views. When I thanked providers for their time, many responded with a thank you in reply. Providers' views on low-income populations matter because they are in the trenches doing the physical and emotional work of trying to keep people healthy. They are unique and have interesting stories to tell. The emotional labor involved in consistently giving people bad news while at the same time trying to counsel them and give them advice about their health can be taxing.

This study also provides an interesting perspective on patient attitudes and perceptions towards STDs through the eyes of health care providers. My research questions were answered, but as I conducted the study, the spectrum of what I wanted to study broadened. The original intention of this research was to focus on women, but as I interviewed more providers I also came to understand that they are only half of the equation. And though most of their patients were women and women are more likely to

acquire an STD because of physiologic reasons (CDC 2004a), this study came to look at 
both males and females in the low-income population of West Virginia. The purpose of this research was to understand experiences of health care providers and receive suggestions about future health care policies. These are important suggestions that could have positive practical implications for low-income patients with sexually transmitted diseases.

This research provided several key findings. The degree of emotional reaction a patient exhibits when diagnosed with an STD is highly influenced by two factors, according to providers. These factors are 1) whether or not infidelity issues arose during the diagnostic session and 2) the type of STD diagnosed. A diagnosis of a viral STD was often the most difficult for a patient and age sometimes affected reactions even though there was no consistent pattern. Patient reactions to STD diagnoses can be grouped into four categories 1) Anger and Sadness, 2) Refusal of Acceptance, 3) Changes in a Patient's Self-Image, and 4) No Reaction. All of these categories emerged from the data and provide a background for the layers of stigma involved in treating STDs in lowincome populations.

Providers spoke openly about dealing with sexually transmitted disease on a daily basis. Providers' reporting of STDs varied but on the whole, reporting of STDs was limited and contributes to researchers overall lack of accurate data on the actual incidence of STDs. Better STD reporting could lead to more money for clinics in desperate need of monetary support. Since HPV and HSV are not required to be reported by law (American Social Health Organization 2005), our statistics on STDs are not accurate.

Providers who treat low-income or uninsured patients on a daily basis consistently see themselves as healers, helpers, and educators and generally exhibit a high level of 
empathy. Sometimes, this empathy is not always evident because experience and many years in practice can translate to a provider/patient space that the provider views as professionalism. This professional distance is often necessary for providers to continue in their line of work without overstretching themselves or "burning” out. However, providers' most certainly have bias in the way they treat patients. The providers I interviewed consistently agreed that in the private sector, provider might mistreat patients without health insurance or low-income patients. If this mistreatment is happening in the private sector, it is most likely happening in the public sector. Providers’ positive views of themselves could be attributed to social desirability and the desire to seem credible to a researcher. But as I indicated earlier in my "Role of the Researcher” section, I was a once a patient at IH and received excellent and thorough care for my annual exam when I did not posses health insurance. This could be because of my education and upper-middle class appearance, but I do not think this is this case. My own biases come into play here, but on the whole I felt that providers were consistently being honest with me and not misrepresenting themselves.

Providers who treat low-income populations deal with special circumstances on a daily basis. Some of the issues they see low-income women struggle with in accessing sexual and reproductive health care include uninsured or underinsured patients, reimbursement problems with Medicare and Medicaid, screening and contraceptive inequality, parental insurance and confidentiality issues when treating underage patients, partner treatment and cost, medication cost, transportation and child care, inconvenient clinic hours, and lack of comprehensive sexual education. Policies that providers feel could help with some of these problems include things like more sexual education in our 
school systems, laws that would protect a provider if they chose to treat the partner of a patient in an adverse event, STD screenings at every annual appointment, more clinics designed specifically for low-income populations, and separate counseling appointments for patients who have recently been diagnosed with an STD.

There were some options that providers did not speak with me about. For example, only one practitioner mentioned socialized medicine as an example of a solution to our health care problems. She did so hesitantly and did not discuss the topic at length. Providers could be afraid of sounding too progressive or too much out of the mainstream. Since their profession depends on exactitude, they were often unwilling to go out on limbs for solutions. Further and more in-depth future research could help to open discussion on more sweeping reforms in healthcare that providers did not speak with me about.

More research is also needed on how providers speak to patients during the diagnostic phase to determine exact provider/patient interactions. However, this kind of research would be extremely difficult because of patient privacy issues and providers could change their behavior when they know they are being watched. The need for further research brings up credibility and dependability (Strauss and Corbin 1998) issues within my research that I have already discussed about providers and social desirability.

My study, like any other, has limitations. The topics in my study include some very sensitive subjects. Sexually transmitted disease can be an uncomfortable subject to discuss, especially when the discussion is about a provider's patient. The provider could have thought that my questions were intrusive and violated the provider/patient confidential relationship. No provider expressed this as a concern, but it could have 
affected the thoroughness of their answers. The providers I interviewed diagnosed STDs multiple times daily which could lead to a jaded perspective that might leave out less STD experienced providers. The view of these seasoned providers could skew the results when trying to generalize to the broader provider population. Also, even though the participants were well-versed in STD diagnoses, they still could have felt uncomfortable during our discussions because of the sensitive nature of the topic. The providers might also have been concerned that I could portray their stories in a negative light. I tried to make it clear to providers that my intentions were scientific and not political to alleviate their concerns and hopefully open up a better dialogue.

The imposing power structure inherent in any interview situation is worth noting. However, it was much less of a limitation during my interviews with providers since all participants at least possessed a high school degree and some college. Physicians, nurse practitioners, and STI educators are familiar discussing research topics with colleagues. However, some of the registered nurses I interviewed were visibly uncomfortable in the interview situation. This could have changed their answers and prevented me from obtaining clear data. I think that the nurses who were uncomfortable during our interview situations did not give me explicit details about their patients. For example, the nurses who discussed diagnosing HIV did not go into unequivocal detail about their feelings being the bearer of a diagnosis of death even though they were prodded.

There are also logistical limitations in my study. The interview sample size is small at 19 participants, with one interview excluded from my analysis. Also, my research locations are not representative of all providers in West Virginia. The providers could have different feelings about their places of employment than other providers 
would in more rural settings, or in more urban settings. Personal feelings about the inside politics of running small community organizations can cloud memory and change actual events. Another limitation of my research is the short interview length. I did not always have time to be as thorough as possible and follow discussion threads that could have proved very interesting. The providers were often rushed because of their busy time schedule. Providers who work for clinics in low-income environments are often pressed for time because when dealing with Medicare and Medicaid reimbursements, or uninsured patients, a larger quantity of patients have to be seen to simply make overhead costs. There are also a large number of people who need free or reduced-cost health care. Clinics are generally very busy places. Frequently, I had to catch providers in between appointments. I did not want to place undue hardship on the providers by taking up too much of their time and as a result, the interview lengths were short at 25-50 minutes.

During my research phase, I attempted to alleviate the ways providers might modify their responses in only positive directions by formulating and asking questions with the least amount of bias possible. This process is consistent with grounded theory research and was aimed at increasing dependability of my study. I also attempted to be encouraging to every participant no matter what they were confiding in me.

This study shows the necessity for more sexual education in our junior high, high school, and university systems. It provides support for introducing STD screenings at every annual appointment, which could help to target missed populations who might have an STD even though they are not necessarily in an at-risk category. It shows why funding is so integral for access to sexual and reproductive health care for not only low-income women, but also for women in every income bracket and also for all men. Specific state 
or federal policies such as protection laws for providers when they treat a partner they have not physically seen could improve STD rates. Separate counseling appointments paid for by health insurance (including Medicare and Medicaid) could facilitate more emotionally healthy patient populations. But most importantly, this research shows a side of health care providers that has only been studied minimally and documents the necessity of better access and treatment services for low-income populations.

Health care providers are central to the physical and emotional health of individuals and communities. Ideally, they are involved in the care of a person from birth until death and are dedicated to their profession. I believe the participants included in my research are dedicated to serving a low-income population. A provider who sticks to helping and treating low-income populations for over thirty years is obviously deeply committed. They must be willing to accept poorer working conditions than their counterparts who treat people with more money. They must deal with barrier after barrier including monetary accountability and a less educated population. Their opinions and views are essential to understanding what low-income or uninsured populations go through when trying to access health care. Conversely, the central role health care providers play in a patient's life can be negative if they have moral views which prevent a patient from receiving the best care possible (Ascribe 2003). Because of the integral role health care providers have in our medical system, I believe they should take their roles and healers seriously and treat patients without bias. However, some bias is always inevitable.

Providers who work with low-income populations see firsthand how poverty can negatively affect someone’s physical and emotional health. Providers who consistently 
work with low-income populations with sexually transmitted disease face many structural problems and have suggestions to offer. These insights offered by providers in this research are indispensable because they can see what people in other professions, including legislators and policy makers, cannot. 


\section{References:}

Adler, Nancy and Marilee Coriell. 1997. “Socioeconomic Status and Women’s Health.” Pp.11-21 in Health Care for Women: Psychological, Social, and Behavioral Influences, 1997, edited by Sheryle J. Gallant, Gwendolyn Puryear Keita, and Renee Royak-Schaler. Baltimore, MD: United Book Press, Inc.

Agency for Healthcare Research and Quality, Rockville, MD. 2003. "Breast and Cervical Cancer Research Highlights.” Program Brief. Retrieved June 10, 2004 from http://www.ahrq.gov/research/breastca.htm

Alexander, Linda Lewis, Judith LaRosa, and Helaine Bader. 2001. New Dimensions in Women's Health. Boston, MA: Jones and Bartlett Publishers.

Altman, Stuart H., Uwe E. Reinhardt, and Alexandra E. Shields. 1998. The Future U.S. Healthcare System: Who Will Care for the Poor and Uninsured? Chicago, IL: Health Administration Press.

American Social Health Organization. 2005. “STD Facts.” Retrieved July 25, 2005 from http://www.ashastd.org/stdfaqs/statistics.html

Ascribe Newswire: Health. 2003. "Stigma, Information Gaps Contribute to Silence on Sexual Health Matter; National Survey Finds Many Women Not Discussing HIV, Other Sexually Transmitted Diseases with Providers or Partners.” Retrieved October 18, 2004 from $\underline{\text { http://search.epnet.com/login.aspx?direct=true\&AuthType=cookie,ip,url,uid\&db=h }}$ $\underline{\text { xh\&an }=11186332}$ 
Beatty, Barbara G. Maureen O’Connell, Takamuru Ashikaga, and Kumarasen Cooper. 2003. "Human Papillomavirus Education in Middle and High School of Vermont.” Journal of School Health, 73(7):253-258.

Bower, Bruce. 2001. "Plight of the Untouchables.” Science News, 160(17):270-271.

Centers for Disease Control and Prevention. 2004a. "Sexually Transmitted Diseases in Women and Infants.” Retrieved June 29, 2004 from http://www.cdc.gov/std/stats/women\&inf.htm

------. 2004b. “Sexually Transmitted Disease Definitions.” Retrieved June 29, 2004 from http://www.cdc.gov/std/stats/casedef.htm

------ 2000. “Tracking the Hidden Epidemics.” Retrieved June 3, 2004 from http://www.cdc.gov/nchstp/dstd/Stats_Trends/Trends2000.pdf

Charmaz, Kathy. 2003. "Grounded Theory: Objectivist and Constructivist Methods.” Pp.249-291 in Strategies of Qualitative Inquiry, edited by Norman K. Denzin, and Yvonna S. Lincoln. Thousand Oaks, CA: Sage Publications.

Chesson, Harrell W., John M. Blandford, Thomas L. Gift, Guoyu Tao, and Katherine L. Irwin. 2004. "The Estimated Direct Medical Cost of Sexually Transmitted Disease Among American Youth, 2000.” Perspectives on Sexual and Reproductive Health, 36(1):11-19.

Creswell, John W. 2003. Research Design: Qualitative, Quantitative, and Mixed Methods Approaches. Thousand Oaks, CA: Sage Publications Inc.

Cutcliff, J.R. 2000. "Methodological Issues in Grounded Theory. Journal of Advanced Nursing, 31( ):1476-1484 
Danielson, Ross, Anita Barbey, Donna Cassidy, Julie Rosenzweig, and Durre Chowdhury. 1999. "Couple-friendly Services in a Metropolitan Sexually Transmitted Disease Clinic: Views of Clients and Providers.” Family Planning Perspectives, 36(4):195-199.

de Bruyn. 2004. "Living with HIV: Challenges in Reproductive Health Care in South Africa.” African Journal of Reproductive Health, 8(1):92-98.

Devault, Majorie L. 1990. Talking and Listening from Women’s Standpoint. Pp.227-250 in Feminist Perspectives on Social Research, 2004, edited by Sharlene Nagy HessBiber and Michelle L. Yaiser. New York: Oxford University Press.

Family Practice Management. 1999. “Teens Seeking STD Services Place Importance on Provider Traits.” 6(10):18.

Fortenberry, J. Dennis, Mary McFarlane, Amy Bleakley, Sheana Bull, Martin Fishbein, Diane M. Grimley, C. Kevin Malotte, and Bradley P. Stoner. 2002. "Relationships of Stigma and Shame to Gonorrhea and HIV Screening.” American Journal of Public Health, 92:378-381.

Frost, Jennifer. 2001. “Public or Private Providers? U.S. Women’s Use of Reproductive Health Services.” Family Planning Perspectives, 33(1):4-12.

Glaser, Barney and Anselm Strauss. 1967. The Discovery of Grounded Theory; Strategies for Qualitative Research. Aldine Publishing Company: Chicago.

Goffman, Erving. 1963. Stigma: Notes on the Management of Spoiled Identity. Englwood Cliffs, NJ: Prentice Hall. 
Hadley, Jack and John Holahan. 2004. "The Cost of Care for the Uninsured: What Do We Spend, Who Pays, and What Would Full Coverage Add to Medical Spending.” Retrieved May 29, 2004 from: http://www.kff.org

Haslegrave, M. 2003. "Incorporating Sexual and Reproductive Health Care in the Medical Curriculum in Developing Countries.” Reproductive Health Matters, 11(21):49-58.

Henry J. Kaiser Family Foundation. 2004. "Health Care and the 2004 Elections: the Uninsured.” Retrieved October 17, 2004 from:

http://www.kff.org/uninsured/loader.cfm?url=/commonspot/security/getfile.cfm\&P ageID $=46466$

------. 2004. "Percent of Women Ages 18-64 Who Report Having Had a Pap Smear Within the Last Three Years, 2000.” Retrieved June 13, 2004 from http://www.statehealthfacts.kff.org/cgi-bin/healthfacts

------.2004. “Women’s Health Insurance Coverage.” Retrieved November 18, 2004 from http://www.kff.org

Hoffman, Catherine and Marie Wang. 2003. "Health Insurance Coverage in America: 2002 Data Update.” Retrieved May 15, 2004, from http://www.kff.org/uninsured/4154.cfm .

Lawless, Sonia and Susan Kippax. 1996. "Dirty, Diseased and Undeserving: The Positioning of HIV Positive Women.” Social Science and Medicine, 43(9):1371-77. Lichtenstein, Bronwen. 2002. "Chronic Sorrow in the HIV-Positive Patient: Issues of Race, Gender, and Social Support.” AIDS Patient Care and STDs, 16(1):27-39. 
-----. 2003. "Stigma As A Barrier to Treatment of Sexually Transmitted Infection in the American Deep South: Issues of Race, Gender and Poverty.” Social Science and Medicine, 57:2435-2445.

Linnehan, Mary Jane E. and Nora Ellen Groce. 1999. "Psychosocial and Educational Services for Female College Students with Genital Human Papillomavirus Infection.” Family Planning Perspectives, 31(3):137-141.

Mellion, Linda Resnik and Melissa Moran Tovin. 2002. “Grounded Theory: A Qualitative Research Methodology for Physical Therapy.” Physiotherapy Theory and Practice, 18:109-120

Mogilevkina, Iryna, Tanja Tyden, and Viveca Odlind. 2001. “Ukrainian Medical Students’ Experiences, Attitudes, and Knowledge About Reproductive Health.” Journal of American College Health, 49(6):269-273.

Nack, Adina. 2002. "Bad Girls and Fallen Women: Chronic STD Diagnoses as Gateways to Tribal Stigma.” Symbolic Interaction, 25(4):463-485.

-----.. 2001. "Damaged Goods: The Sexual Self-Transformations of Women with Chronic STDs.” PhD dissertation, Department of Sociology, University of Colorado, Boulder.

Neff, James Alan, Sharon P. Gaskill, Jean A. Smith, Mark Weiner, Thomas J. Prihoda, Rachel V. Weiner, Herbert P. Brown, and Edward Newton. 1998. "Preliminary Evaluation of Continuing Medical Education-Based Versus Clinic-Based Sexually Transmitted Disease Education Interventions for Primary Care Practitioners.” Teaching and Learning in Medicine, 10(2):74-82. 
O’Connell, Mary Lee. 1997. “Communication: The Key to Decreasing Unintended Pregnancy and Sexually Transmitted Disease/HIV Risk.” Journal of Perinatal Education, 6(1):35-42.

Pamuk, Heck, Reuben, and Lochner 1998. Health, United States. Socioeconomic Status and Health Chartbook. Hyattsville, MD: U.S. Dept. of Health and Human Services, Centers for Disease Control and Prevention, National Center for Health Statistics. Proctor, Bernadette D. and Joseph Dalaker. 2003. "Poverty in the United States: 2002.” Retrieved June 5, 2004, from http://www.census.gov/prod/2003pubs/p60-222.pdf

Rosser, Sue V. 1994. Women's Health—Missing From U.S. Medicine. Indiana University Press: Bloomington and Indianapolis, IN.

Schatzman, Leonard. 1991. Dimensional Anyalysis: Notes on an Alternative Approach to the Grounding of Theory in Qualitative Research. Pp 303-314 in Social Organizations and Social Processes: Essay in Honor of Anselm Strauss, 1991, edited by David Maines. New York: Aldine de Gruyter.

Singh, Susannah, Jacqueline Darroch, and Jennifer Frost. 2001. "Socioeconomic Disadvantage and Adolescent Women’s Sexual and Reproductive Behavior: The Case of Five Developed Countries.” Family Planning Perspectives, 33(6):251$258+289$.

Skouby, S.O. 2004. "Contraceptive Use and Behavior in the $21^{\text {st }}$ Century: A Comprehensive Study Across Five European Countries. European Journal of Contraception \& Reproductive Health Care, 9(2):57-68.

Spongberg, Mary. 1997. Feminizing Venereal Disease. New York: New York University Press. 
Strauss, Anselm and Juliet Corbin. 1998. Basics of Qualitative Research: Techniques and Procedures for Developing Grounded Theory. Sage Publications, Incorporated: Thousand Oaks, California.

University of Chicago Hospitals. “Women’s Health Homepage.” Retrieved July 25, 2005 from http://www.uchospitals.edu/online-library/content=P01521\#P

Waldrop, Judith 2000. “Population profile of the United States.” Retrieved June 5, 2004 from http://www.census.gov/population/www/pop-profile/profile2000.html

Weinstock, Hillard, Stuart Berman, Willard Cates Jr. 2004. “Sexually Transmitted Diseases Among American Youth: Incidence and Prevalence Estimates, 2000.” Perspectives on Sexual and Reproductive Health, 36(1):6-10.

Wen, Ming, Christopher R. Browning, Kathleen A. Cagney. 2003. "Poverty, Affluence, and Income Inequality: Neighborhood Economic Structure and its Implications for Health.” Social Science \& Medicine, 57(5):843-860.

Wortmann, Susan. 2003. “Women's Reproduction: Issues and Inequalities in the $21^{\text {st }}$ Century.” Society for Women in Sociology, xx(1):4-5.

Wyn, Roberta, Victoria Ojeda, Usha Ranji, Alina Salganicoff. 2004. "Health Coverage and Access Challenges for Low-income Women: Findings from the 2001 Kaiser Women’s Health Survey.” Retrieved June 29, 2004 from http://www.org/womenshealth/loader.cfm?url=/commonspot/security/getfile.cfm\& $\underline{\text { PageID }=33095}$ 


\title{
Appendix A
}

\section{IRB Approval Forms}

\author{
WestVirginiaUniversity \\ Office of Research Compliance \\ DATE: November 23, 2004 \\ This research will be monitored for re-approval annually. \\ APPROVAL PERIOD: November 23, 2004 to November 22, 2005 \\ NOTICE OF APPROVAL FOR PROTOCOL: IRB \#16407 \\ TO: Genevieve Cox \\ TITLE: Sexually Transmitted Disease and Socioeconomic status: \\ What Health Care Providers Say About Access to Sexual Health \\ Care for Low-Income Women in West Virginia \\ AGENCY : N/A \\ The Institutional Review Board for the Protection of Human \\ Research Subjects (IRB) has approved the project described \\ above. Approval was based on the descriptive material and \\ procedures you submitted for review. Should any changes in \\ your protocol/consent form be necessary, prior approval must \\ be obtained from the IRB. \\ According to the Code of Federal Regulations, Section \\ 312.32 , investigators are required to notify the FDA and the \\ study sponsor of any adverse experience associated with the use \\ of an investigational drug that is serious and unexpected. A \\ serious adverse experience is considered any event that is fatal \\ or life-threatening, is permanently disabling, requires \\ inpatient hospitalization, or is a congenital anomaly, cancer, \\ or overdose. An unexpected adverse experience is an event that \\ is not identified in nature, severity, or frequency in the \\ current investigator brochure. Any experience reportable to FDA \\ and the sponsor must also be reported immediately to the IRB. If \\ the study is funded, initiation of the protocol may not begin \\ until the contract is finalized.
}


Date: November 23,2004

Page -2-

Cox

IRB \#16407

A consent form* $\mathrm{x}$ is is not required of each subject.

An assent form is $\mathrm{X}$ is not required of each subject.

A recruitment ad has has not $\mathrm{X}$ been approved.

A consent form waiver has has not $\mathrm{X}$ been approved.

An authorization form to use PHI has has not $\mathrm{X}$ been approved.

A PHI waiver has has not $\mathrm{X}$ been approved.

Only copies of the consent and/or assent form with the IRB's approval stamp may be used with human subject research. It is the responsibility of the investigator to submit a revised consent form for the IRB's approval should funding be obtained. This stamped consent form must then be used for subjects enrolled. A copy of each subject's signed Consent/Assent Form must be retained by the investigator and accessible to federal regulatory authorities for at least three years after the study is completed.

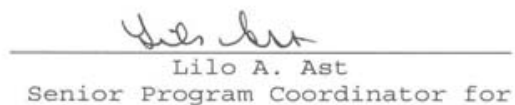
Senior Program Coordinator for Research Compliance

$\mathrm{LAA} / \mathrm{Clg}$ 


\section{Appendix B}

\section{Consent and Information Forms}

\author{
West VirginiaUniversity \\ Eberly College of Arts and Sciences
}

CONSENT AND INFORMATION FORM

"Sexually Transmitted Disease and

Socioeconomic Status: What Health Care Providers

Say About Access to Sexual Health Care

for Low-Income Women in West Virginia"
WEST VIRGINIA UNIVERSITY Institution Review Board for the
Protection of Human Research Subjects

NOV 232004

1 - APPROVED

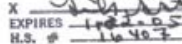

IRB Approval Stamp

Introduction: have been invited to participate in this research study which has been explained to me by Genevieve Cox. This research is being conducted by Genevieve Cox to fulfill the requirements for a master's thesis in Applied Social Research in the Division of Sociology and Anthropology at West Virginia University, under the supervision of Melissa Latimer, $\mathrm{PhD}$.

Purposes of the Study:

The purpose of this study is to learn more about what health care provider's have to say about access to sexual health care for low-income women with sexually transmitted diseases. Approximately 18-22 people are expected to participate in this study.

Genevieve Cox will compile these interviews into a narrative to add to the breadth of knowledge on socioeconomic status and women's health.

Description of Procedures:

This study involves face-to-face interviews with health care providers, which will take approximately 45 minutes for me to complete. I understand that I may see all the questions that Genevieve Cox will be asking me prior to signing the consent form and that I do not have to answer all of the questions. I understand that she will be audio taping the interview.

Risks and Discomforts:

There are no known or expected psychological risks from participating in this study, except for the emotions involved when recalling certain aspects of my occupation.

Most Recent IRB Submission:

$11 / 10 / 2004$

Page 1 of 3

School of Applied Social Sciences

Division of Soclology and Anthropology

Participant's Initials/Date

gy


WestVrginiaUniversity

Eberly College of Arts and Sciences

"STD and SES: What Providers

IRB Approval Stamp

Say About Access to Sexual Health Care

for Low-Income Women in WV"

\author{
Alternatives: \\ I understand that I do not have to participate in this study. \\ Benefits: \\ I understand that this study may not have a direct benefit to me, but the knowledge \\ gained may be of benefit to others and to the organization for which I work.
}

\title{
Contact Persons:
}

For more information about this research, I can contact Genevieve Cox, at 304-685-2441

or her supervisor, Melissa Latimer,PhD at 304-293-5801, extension 3209. For

information regarding my rights as a research subject, I may contact the Office of

Research Compliance at 304-293-7073.

\section{Confidentiality:}

I understand that any information about me obtained as a result of my participation in this research will be kept as confidential as legally possible. I understand that my research records and test results, just like hospital records, may be subpoenaed by court order or may be inspected by the study sponsor or federal regulatory authorities, or the IRB without my additional consent. In any publications or presentations that result from this research, neither my name nor any information from which I might be identified will be used without my consent. The audio tapes of my interviews with Genevieve Cox will be destroyed by February $15^{\text {th }}, 2005$.

Most Recent IRB Submission

Participant's Initials/Date

$11 / 10 / 2004$

Page 2 of 3

School of Applied Social Sciences

Division of Sociology and Anthropology

Phone: 304-293-5801

307 Knapp Hall

$\begin{array}{ll}\text { Fax: } 304-293-5994 & \text { PO Box } 6326\end{array}$

www.as.wvu.edw/soc_al Morgantown, wV 26506-6326

Equal Opportunity/Affirmative Action Institution 


\section{WestVirginiaUniversity \\ Eberly College of Arts and Sciences}

"STD and SES: What Providers

IRB Approval Stamp

Say About Access to Sexual Health Care

for Low-Income Women in WV"

Voluntary Participation:

Participation in this study is voluntary. I understand that I am free to withdraw my

consent to participate in this study at any time and that such refusal to participate will not

affect my future care. Refusal to participate or withdrawal will involve no penalty to me.

I have been given the opportunity to ask questions about the research, and I have received answers concerning areas I did not understand.

Upon signing this form, I will receive a copy.

I willingly consent to participate in this research.

\begin{tabular}{lll}
\hline Signature of Participant & Date & Time
\end{tabular}

Signature of Investigator

Date

Time

Most Recent IRB Submission

Participant's Initials/Date

$11 / 10 / 2004$

Page 3 of 3

School of Applied Social Sciences

Division of Sociology and Anthropology

Phone: $304-293-5801$

Fax: 304-293-5994

307 Knapp Hall

307 Knapp Hall

Morgantown, WV 26506-6326 Equal Opportunity/Affirmative Action Institution 


\section{Appendix C}

\section{Interview Questions}

1. How many years have you been working in women's health care? At IH?

2. What is the time commitment of some one who comes for an appointment at each of your clinics? (i.e. Family Planning, STD Clinic, HIV Testing/Counseling, BCCSP)

3. Do you think a lot of STDs don't get reported?

a. If yes, why?

b. Should all STDs be reported regardless of how it makes the patient feel?

4. Do you have goals in doing the kind of work that you do?

a. If so, what are they?

5. How do you see your job? Give me three main points that would describe how you see your profession.

6. What is the process/script that is followed when giving a patient a specific STD diagnosis? If respondent answers this is a difficult job:

a. Could anything be done to make this process easier, if you feel that this is a difficult job?

7. How much time do you spend with each patient when giving a diagnosis?

8. On a scale of 1 to 5 with 1 being the easiest and 5 being the most difficult, how emotionally difficult is it to give an incurable STD diagnosis?

a. Has the job of giving diagnoses gotten easier or harder since you've been here and why?

9. Do you remember any specific incidences (without mentioning names or other sensitive material) in which a patient reacted negatively to an STD diagnosis?

10. What are some of the words/key phrases that patients use when diagnosed with specific STDs?

11. In your opinion does an STD diagnosis change how a patient feels about their sexuality? Or is this not something that you come in contact with directly?

12. What is the age group of most of the patients you see here?

13. If you see mostly women under age 25 , do you feel that they have a more difficult time dealing with an STD diagnosis than some one older? Why or why not? 
14. Do you think that women without health insurance or low-income women (changed to some individuals) have a more difficult time dealing with an STD? Why or why not?

15. What are the most reoccurring issues that you see involved in lowincome/uninsured women's sexual health care?

16. Are there any specific policies that you would like to see implemented that could help either

a. you do your job more effectively? Or

b. help the women have better treatment/prevention services?

17. In your opinion, does having or not having health insurance make a difference in how a group of patients are treated in WV?

i. Does one group of patients receive better care than another?

1. Why?

18. Do you think the sex of a health care provider affects a woman's treatment and/or experience? Why or why not? 


\section{Appendix D}

\section{Categories and Subcategories within the Findings}

\section{STD Reporting (category)}

1. STD Nonreporting Assent (subcategory)

a. Some STDs are Nonreportable (dimensions of experience)

b. STD Detection

c. Some Providers Don't Know How to Report

d. Some STDs Diagnoses are made Clinically

e. STDs Unnecessary to Report

f. STDs Difficult to Report

g. Partners go Unreported

2. STDs Are Reported

a. Misnomer that STDs are Actually Reported

b. STDs Should be Reported

c. Lab Tests and Goes to Reporting

3. STD Reporting Disregarding Patients Feelings

a. STD Reporting when Public Health Issue

\section{STD Diagnostic Sessions}

1. First time Diagnosis/Partner Infidelity

2. Diagnosis of a Viral versus Bacterial STDs

a. STDs (non HIV/AIDS)

b. HIV/AIDS

3. Time in Diagnostic Sessions

a. Dependant on STD-Variation

4. Scripts/Protocol Followed

5. Unrelated Illness Becomes Related to STD and Surprises Patient

6. "Repeat Offenders"

7. Viral STDs Carry a Larger Stigma

\section{Patient Reactions to STD Diagnoses}

1. Anger and Sadness

a. Anger at Partner

b. Tears/Sadness

c. "Nobody will want to go out with me."

2. Refusal of Acceptance

a. Handling Future Sexual Discussions

b. "How could I get this?"

3. Change in Patient's Self-Image

a. Abstinence and "I'm never going to have sex again."

b. Dirty/Diseased

c. Self-Judgment 
4. No Reaction

\section{STD and Age}

1. Younger Patients and STD Diagnoses

2. Older Patients and STD Diagnoses

\section{Provider Goals}

1. Education

a. Patient Education

b. Med Student Education

2. To Be a Healer

3. To Be a Helper

4. Positive Diagnostic Experience

\section{Provider's Views of Patient's Sexuality}

1. Minimalization of Diagnosis Changing Sexuality

2. Stigma Attached to STD Changes Patient's View

3. Sobers a Patient

\section{Providers and Sensitivity}

1. Treating Uninsured Patients Differently

2. Emotional Reaction from Patient During Diagnosis Increases Difficulty for Provider

3. How STDs Make Provider Feel

4. Providers Becoming Desensitized to STDs

5. Private Providers Versus Public Providers -Working with Low-Income and/or Young Populations

6. How Providers See Their Job

7. Diagnosing STDs and Sensitivity

8. Diagnoses Becoming Easier Over Time for Providers

\section{Issues Which Limit Low-Income Women's Access to Care}

1. Health Insurance

a. Medicare, Medicaid, and Coverage Issues

b. Insured Patients Receiving More Comprehensive Care

c. Young Patients on Parental Health Insurance and Privacy Issues

2. Transportation and Child Care

3. Low-Paying Jobs and Appointment Times

4. Higher Income Women have more Difficult Time with STD Diagnosis

5. Domestic Violence and Rape

6. Education Levels

7. Drug Abuse

8. Partner Treatment and Support Systems

9. Cost and Availability of Medications

10. Organizational Ability 
11. Provider Consistency (Medical Home)

12. Clinic Availability

\section{Policies Providers Advocate}

1. Sexual Education
a. Abstinence-Only Education
b. Starting Early
c. Evolving with Changing Practices

2. Treating Partners -Protection Laws for Provider

3. STD Screening at Every Annual Appointment for Every Person (Population Targeting)

4. Need for More Clinics and Funding

5. Contraceptive Equality

6. More Scheduling/Counseling Time

a. Not Having Enough Diagnostic Time to Counsel

b. Need for Separate Counseling Appointments 


\section{Curriculum Vita}

\section{GENEVIEVE COX}

\section{SKILLS}

- Excellent office and communication skills including PC computer skills and internet research

- Television and commercial production experience

- Qualitative and quantitative data management and analysis. Qualitative data gathering techniques such as interviews and ethnography.

- Ability to conduct literature reviews and write press releases with proficiency

- Experience with SPSS data analysis program and DPS Velocity editing system

\section{RESEARCH INTERESTS}

- Thesis Topic: Health Care Providers' Attitudes of Low-income Populations with Sexually Transmitted Disease

- Other Research Interests: Qualitative Research, Reproductive Health Care, Inequality, Feminist Theories

\section{EXPERIENCE}

January 2004-Present West Virginia University Health Sciences Center Morgantown, WV

Graduate and Production Assistant in Planning, Marketing, and Communications

I. Help in development of content for 2004 and 2005 Children's Miracle Network live broadcast telethons.

- Work with various writing and editing assignments including press releases, content outlines for a weekly radio and television show, television health reports, and office correspondences.

- Assistance in planning of television commercial shoots, media relations, record keeping, and continuing medical education conference organizing.

Plainfield, MA

\section{Earthdance}

\section{Retreat Center Intern}

- Direction of various dance workshop attendees and assisted in the development of the yearly Earthdance newsletter.

Summers of 2002 and 2003

Tuxedo, NC

Around Camp Activities Head Instructor, Mountain Bike Instructor, and Counselor

- Scheduled and managed activities for a staff of counselors and approximately 70 children.

- Oversaw cabins of teenaged girls.

- Instructed the fundamentals of mountain biking and backpacking. 


\section{Assistant Director, Backstage Manager}

- I assisted in the direction of the summer musical and managed the backstage area of a theater.

Winter 2000-2001

\section{Snowshoe Mountain}

Snowshoe, WV

Ski Instructor

- Instruction of the fundamentals and advanced technique of skiing to both children and adults.

\section{EDUCATION}

1999-2002

Ohio University

Athens, $\mathrm{OH}$

- B.A., English, Theater Minor

- Graduated in only three years while maintaining Dean’s List Status

2003-2005

West Virginia University

Morgantown, WV

- M.A., Applied Social Research, Graduate Certificate in Women's Studies

Affiliations: Member of American Sociological Association, Younger Women's Task Force, Sociologists for Women in Society

Awards: $2^{\text {nd }}$ Place Winner of Velma Miller award for an outstanding graduate student in women's studies-2005. 